\title{
Avaliação quantitativa e qualitativa de resíduos de pescados em três feiras livres,
} Marabá, Pará

\author{
Quantitative and qualitative evaluation of fish waste in three open markets, Marabá, Pará \\ Evaluación cuantitativa y cualitativa de los residuos de pescado en tres mercados abiertos, Marabá, \\ Pará
}

Recebido: 29/03/2021 | Revisado: 08/04/2021 | Aceito: 10/04/2021 | Publicado: 21/04/2021

\author{
Antônio Pereira Júnior \\ ORCID: https://orcid.org/0000-0001-6241-985X \\ Universidade do Estado do Pará, Brasil \\ E-mail: antonio.junior@uepa.br \\ Mikaele Machado Oliveira \\ ORCID: https://orcid.org/0000-0002-8808-0935 \\ Universidade do Estado do Pará, Brasil \\ E-mail: mikaelemachado7@gmail.com \\ Stephani Gomes Feitosa \\ ORCID: https://orcid.org/0000-0002-7697-2987 \\ Universidade do Estado do Pará, Brasil \\ E-mail: stephanifeitosa@hotmail.com
}

\begin{abstract}
Resumo
O objetivo desta pesquisa foi avaliar a geração de resíduos de pescado e a percepção ambiental dos peixeiros quanto aos impactos ambientais causados pelo armazenamento temporário e a disposição final dos resíduos gerados em três feiras livres do município de Marabá - Pará. O método utilizado foi o indutivo com abrangência quantitativa e qualitativa. Foram efetuadas quatro visitas in loco, para obtenção de dados primários. Os secundários foram obtidos em links eletrônicos de acesso livre. A análise dos dados obtidos indicou que são comercializados nove gêneros de pescados; a maior quantidade comercializada ocorreu na Feira da $28(2.114,9 \mathrm{~kg} / \mathrm{mês})$; foram identificados e

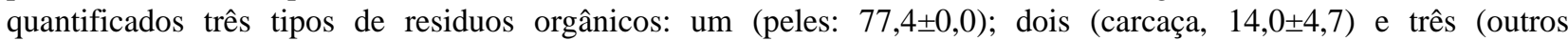
$88,4 \pm 21,6)$; o armazenamento temporário é realizado em baldes $(8,3 \pm 1,5)$ e sacos plásticos de $100 \mathrm{~L}(2,3 \pm 1,5)$, foi observada que não há segregação residual $(6,7 \pm 3,1)$; todos os indivíduos amostrados $(n=36: 100 \%)$ informaram que os resíduos coletados pela prefeitura, são destinados ao aterro controlado sem o tratamento adequado. Em relação a percepção ambiental de impactos causados pelo descarte inadequado, ainda há desconhecimento disso $(7,0 \pm 2,0)$; a grande maioria deles não tem conhecimento sobre as alternativas sustentáveis para os resíduos orgânicos $(7,3 \pm 0,6)$, mas a minoria conhece $(3,7 \pm 2,9)$, e citaram ração animal $(5,0 \pm 2,7)$ e adubo orgânico $(2,0 \pm 3,1)$ como solução adequada. Logo, as condições higiênico sanitárias nas três feiras não são adequadas e que necessitam urgentemente de correções para adequação às legislações sanitárias e ambientais como, por exemplo, a Resolução CONAMA 275/01.

Palavras-chave: Impactos ambientais; Diagnóstico ambiental; Feirantes.
\end{abstract}

\begin{abstract}
The objective of this research was to evaluate the generation of fish waste and the environmental perception of fishmongers regarding the environmental impacts caused by temporary storage and final disposal of waste generated in three open markets in the city of Marabá - Pará. The method used was inductive with quantitative and qualitative comprehensiveness. Four in loco visits were made to obtain primary data. The secondary data were obtained from free access electronic links. The analysis of data obtained indicated that nine kinds of fish are commercialized; the largest quantity occurred at the fair of $28(2.114 .9 \mathrm{~kg} / \mathrm{month})$; three types of organic waste were identified and quantified: one (skins: $77.4 \pm 0.0$ ); two (carcass, $14.0 \pm 4.7$ ) and three (others $88.4 \pm 21.6$ ); temporary storage is done in buckets $(8.3 \pm 1.5)$ and $100 \mathrm{~L}$ plastic bags $(2.3 \pm 1.5)$, it was observed that there is no residual segregation $(6.7 \pm 3.1)$; all sampled individuals $(\mathrm{n}=36: 100 \%)$ reported that the waste collected by the municipality, is destined to the controlled landfill without proper treatment. Regarding the environmental perception of impacts caused by improper disposal, there is still ignorance about it (7.0 \pm 2.0$)$; the vast majority of them have no knowledge about the sustainable alternatives for organic waste (7.3 \pm 0.6$)$, but the minority knows $(3.7 \pm 2.9)$, and they cited animal feed (5.0 \pm 2.7$)$ and organic manure $(2.0 \pm 3.1)$ as appropriate solutions. Therefore, the hygienic and sanitary conditions in the three markets are not adequate and urgently need corrections to adapt to the sanitary and environmental laws, such as Resolution CONAMA 275/01.
\end{abstract}

Keywords: Environmental impacts; Environmental diagnosis; Marketers. 


\begin{abstract}
Resumen
El objetivo de esta investigación fue evaluar la generación de residuos de pescado y la percepción ambiental de los pescaderos respecto a los impactos ambientales causados por el almacenamiento temporal y la disposición final de los residuos generados en tres mercados abiertos de la ciudad de Marabá - Pará. El método utilizado fue inductivo con alcance cuantitativo y cualitativo. Se realizaron cuatro visitas in situ para obtener datos primarios. Los datos secundarios se obtuvieron de enlaces electrónicos de libre acceso. El análisis de los datos obtenidos indica que se comercializan nueve tipos de pescado; la mayor cantidad comercializada se produjo en la Feria del 28 (2. 114,9

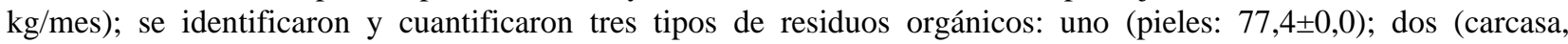
$14,0 \pm 4,7)$ y tres (otros $88,4 \pm 21,6)$; el almacenamiento temporal se realiza en cubos $(8,3 \pm 1,5)$ y en bolsas de plástico de $100 \mathrm{~L}(2,3 \pm 1,5)$, se observó que no hay segregación residual $(6,7 \pm 3,1)$; todos los individuos muestreados $(\mathrm{n}=36$ : El 100\%) informó de que los residuos recogidos por el municipio se destinan al vertedero controlado sin el tratamiento adecuado. En cuanto a la percepción ambiental de los impactos causados por la eliminación inadecuada, sigue habiendo desconocimiento de esta $(7,0 \pm 2,0)$; la gran mayoría no tiene conocimientos sobre las alternativas sostenibles para los residuos orgánicos $(7,3 \pm 0,6)$, pero la minoría sí los conoce $(3,7 \pm 2,9)$, y citaron la alimentación animal $(5,0 \pm 2,7)$ y el abono orgánico $(2,0 \pm 3,1)$ como solución adecuada. Así, las condiciones higiénicas y sanitarias de los tres mercados no son adecuadas y necesitan correcciones urgentes para adaptarse a las leyes sanitarias y ambientales, como la Resolución CONAMA 275/01.
\end{abstract}

Palabras clave: Impactos ambientales; Diagnóstico ambiental; Vendedores del mercado.

\title{
1. Introdução
}

Os resíduos de pescados encontrados em feiras livres são dispostos em aterros e vazadouros a céu aberto, o que configura como poluição ambiental (Costa, 2016). Nessa perspectiva, a quantidade de resíduo de pescado varia conforme as espécies que são comercializadas, resultando em descartes de até $65 \%$ do peso de pescado, ao passo que $35 \%$ são poupados (Valente et al., 2014).

Nessa perspectiva, as feiras livres são locais de grande comercialização de peixe, onde os pontos de vendas possuem grande precariedade em relação ao manejo e estocagem de seus resíduos gerados (Pinto et al., 2011). Esse processo desencadeia quantidade elevada de resíduos da própria matéria-prima do peixe, tais como cabeça, cauda, ossos, escamas, restos de carne e vísceras, dependendo da espécie comercializada e que possui baixo valor comercial (Pires et al., 2014).

O peixe, no conceito descrito no Decreto n. ${ }^{\circ} 9,013$ (2017), artigo $439 \S 1^{\circ}$ : o pescado que é comercializado sem que tenha havido qualquer outro processo de conservação que não o gelo. No Brasil, a produção e o consumo de pescado são crescentes a cada ano, como demonstra os dados obtidos pelo Instituto Brasileiro de Geografia e Estatística (IBGE), em 2016 a produção foi de 507,12 mil toneladas de peixe, comparado ao ano de 2015 que produziu 484,81 mil toneladas, um aumento de 4,4\%. O Ministério da Agricultura também destacou que o consumo estimado no País é de 14,4kg por habitante/ano.

Como consequência dessa demanda, a comercialização de pescado in natura nos municípios brasileiros inclui-se como fontes geradoras de resíduos, logo as alternativas de descarte correto, redução do desperdício ou reaproveitamento de material é um fato carente no que tange essas atividades (Galvão \& Oetterer, 2014). Além disso, a falta de gerenciamento correto dos resíduos é outro fator importante, principalmente nas etapas de acondicionamento, segregação, armazenamento e coleta associado a falta de estrutura e planejamento (Silva \& Andreoli, 2010).

Nesse ponto de vista, os resíduos de pescados que são produzidos tais como sobra de partes, escamas, sangue, vísceras e carcaças, são comumente descartados poluindo o meio ambiente, pois a deterioração é encarregada pela oxidação e pelas atividades microbianas (Soares et al., 2011). Os descartes são realizados durante o processamento e depende da espécie de peixe que está sendo comercializado (Nascimento et al., 2018).

Por outro lado, esses resíduos podem ser utilizados como ingredientes na fabricação de farinha e ração para alimentação animal, ou como adubo orgânico, pois é uma fonte de nutrientes, como nitrogênio $(\mathrm{N})$, potássio $(\mathrm{K})$ e fósforo $(\mathrm{P})$ para as plantas (Decker et al., 2016). Dessa forma, ao substituir a utilização de fertilizantes químicos em agriculturas, estimula o desenvolvimento sustentável e reduz os impactos ambientais (Bruno et al., 2013). 
Todavia eles possuem uso sustentável como, por exemplo, na elaboração de coprodutos dessa matéria prima podem surgir novos produtos a partir dessas sobras de pescado, assim agregando valor ao produto (Pinto et al., 2017). Com isso, para determinar o balanço de massa final dessas sobras pode ser caracterizado de acordo com o cálculo de rendimento, de modo que tenha a relação do peso inicial do pescado e o peso dos resíduos gerados (Amorim, 2014).

Sobre todos esses aspectos, é importante a identificação da percepção ambiental quanto aos estímulos que os indivíduos assimilam, sejam externos ou internos, em face da atividade desenvolvida e o quanto o meio em que vivem, significa quanto ao formato, o sentido e a interação dele com o que consegue perceber quanto a conservação, preservação, impactos ambientais, dentre outros (Lucena, 2010).

Portanto, a aplicação de alternativas que visem o aproveitamento desses resíduos para outros fins, a contribuição para não poluição ambiental e sanitária. Esses argumentos justificaram e incrementaram a relevância desta pesquisa, e permitiram a elaboração do objetivo que foi: 1) tipificação, quantificação, a segregação, acondicionamento externo, a coleta dos resíduos orgânicos e as condições higiênicos sanitárias nos setores de pescados; 2) a percepção dos feirantes acerca dos resíduos sólidos por eles gerados e o ambiente onde labutam quanto a essas etapas, e 3) sugerir alternativas para melhor gerenciamento desse tipo de resíduo.

\section{Revisão de literatura}

\subsection{Resíduos do pescado}

O descarte dos resíduos de pescados, quando não tratado, polui o meio ambiente e sua deterioração é encarregada pela oxidação e pelas atividades microbianas (Soares et al., 2011). Sobretudo, os impactos ocasionados é consequência da formação de ácidos orgânicos, tais como o chorume, que é um líquido com alta Demanda bioquímica de oxigênio - DBO (Decker et al., 2016). No que tange a apresentação desses resíduos, eles são encontrados em dois locais que possuem esses tipos de atividades exercidas pela comunidade: (1) podem ser no ato da pesca e que não é ofertado para comercialização e apenas para captura; (2) durante a venda que são feitas através da comercialização do peixe em feiras livres, por meio de filetagem e limpeza (Kefalas, 2011).

Após a geração, eles devem ter destinação correta e quando são alocados em áreas inadequadas como, por exemplo, terrenos baldios, a decomposição deles favorecem o surgimento de germes patogênicos e vetores. O gerenciamento incorreto, juntamente com falta de coleta, ausência de transporte correto e destinação final adequada, afeta seriamente o paisagismo (Oliveira et al., 2012). Nesse sentido, as contaminações em aquíferos são causados por aterros e lixões através da infiltração de chorume contaminando grande parte de córregos e rios (Lins et al., 2010).

\subsection{Geração dos resíduos do pescado em feiras livres}

Os números para esses tipos de feiras, no Brasil, são elevados. De acordo com o Ministério do Desenvolvimento Social (MDS), em 1628 municípios, existem 5.119 áreas com essa finalidade. Outro fator atrativo desses locais, são: 1) variedade de produtos; 2) presença de agricultores da região. O ponto negativo e a exposição dos diversos tipos de alimentos a contaminações como, por exemplo, manipulação inadequada, resíduos sólidos orgânicos acumulados por horas, ao derredor desses locais, onde proliferam principalmente, moscas dentre outros (Silva et al., 2020).

Nas feiras livres, principalmente nos boxes de comercialização, há um quantitativo expressivo de resíduos de pescado, com uma geração média de 23,63t (Santos, 2016) como restos de carnes, nadadeiras e escamas, que são armazenados de forma exposta e inadequada, além da presença de gases com odores desagradáveis e a circulação de animais domésticos (Martins, 2015). Dessa forma, a oferta de tecnologias para aproveitamento dos resíduos gerados em feiras livres, grande parte desse material ainda é mal aproveitado, sendo depositado de forma indiscriminada e inadequada, principalmente em caçambas de 
metal junto aos demais tipos de resíduos orgânicos e recolhidos por caminhão coletor de resíduos, o que acarreta graves problemas ambientais (Medeiros Júnior et al., 2015).

\subsection{Impactos ambientais a partir dos resíduos de pescado}

$\mathrm{O}$ chorume $\left(\mathrm{C}_{5} \mathrm{H}_{14} \mathrm{~N}_{2}\right)$ é extremamente poluente, pois trata-se de um líquido que possui alta carga orgânica e uma composição química diversificada, assim em contato com meio ambiente as cargas contaminantes do lixiviado apresentam-se em diferentes substâncias, como: nitrogênio $(\mathrm{N})$, em forma amoniacal, como nitrato $\left(\mathrm{NO}_{-3}\right)$, nitrito $\left(\mathrm{NO}_{-2}\right)$, amônia $\left(\mathrm{NH}_{3}\right)$, ou em forma de halogênico, como cloreto $\left(\mathrm{Cl}^{-}\right)$, carbonato $\left(\mathrm{Na}_{2} \mathrm{CO}_{3}\right)$, e também metais, como manganês $(\mathrm{Mn})$, zinco $(\mathrm{Zn})$, níquel (Ni) e cobre $(\mathrm{Cu})$ dentre outros (Vallejo \& Monteiro, 2014).

Quando não há aplicação de alternativas sobre estes resíduos, podem resultar na contaminação do solo, do ar e dos corpos d'água (Sanes et al., 2015). Os locais de disposição final dos resíduos de pescado são os lixões, aterros sanitários, rios, córregos e mares dentre outros locais. Estes resíduos são caracterizados como contaminantes pois há a liberação de gases com odores desagradáveis, a poluição da água subterrânea e poluição visual (Bendito et al., 2017).

Em especial, os resíduos de pescado possuem um grande potencial para aplicação em tecnologias para o desenvolvimento sustentável, pois a insuficiência de gerenciamento correto e a falta de conhecimento sobre alternativas viáveis para estes resíduos ocasiona um enorme desperdício desses resíduos (Bery, 2012). Nesse parâmetro, o pescado apresenta pH próximo a neutro e é de fácil deterioração pois apresenta elevada quantitativo de água nos tecidos, além de ações enzimáticas nas vísceras e alto teor de nutrientes que são aproveitados pelos microrganismos (Soares \& Gonçalves, 2012).

Nesse enfoque, o problema sanitário também tem grande relevância, pois a grande geração de resíduos orgânicos ocasiona doenças epidemiológicas a comunidade, principalmente pela falta de estrutura nos locais de vendas, resultando na presença de vetores e proliferação de patógenos, e de animais domésticos (Amorim, 2014).

\subsection{Sustentabilidade}

O modelo de desenvolvimento mundial contribui para a crescente geração de resíduos sólidos, ocasionando problemas socioambientais, tornando necessária a adoção de mudanças para atender essa nova era, um novo modelo de desenvolvimento sustentável, pois essas coações sobre o meio ambiente advêm dos fatores culturais, econômicos, sociais e políticos, sendo assim, o que se deseja é o equilíbrio entre esses fatores (Santos, 2012).

Nesse parâmetro, a Lei 11.959 (2009) trata sobre a Política Nacional de Desenvolvimento Sustentável da Aquicultura e da Pesca aprimora sobre a sustentabilidade dos recursos pesqueiros harmonizando os benefícios econômicos e a preservação, recuperação e conservação do meio ambiente. Nesse contexto, o desenvolvimento sustentável tem como objetivo defender os ecossistemas, mas aliado as indigências socioeconômicas da população assegurando atender as atuais e futuras gerações (Glowka et al., 2018).

Minimizar os impactos e inibir a geração desses resíduos orgânicos é fundamental embora ainda seja limitado o conhecimento de alternativas sustentáveis (Melo et al., 2011). A adoção de políticas públicas voltadas para a realidade local da região contribui para o desenvolvimento pesqueiro, tomando como base o aproveitamento dos resíduos de pesca por apresentarem valores de usos sustentáveis ao invés de serem descartados (Oliveira, et al., 2012).

\subsection{Política Nacional de Resíduos Sólidos (PNRS)}

Acerca dessa política, sabe-se que ela tem apoio jurídico na Lei 12. 305 (2010). Nela, está contida a regulamentação quanto a prestação de serviços públicos e de limpeza urbana, o manejo correto dos resíduos sólidos. O incentivo para coleta seletiva, a compostagem, a logística reversa, até mesmo a eliminação dos vazadouros a céu aberto. Neste caso, a criação de 
projetos do poder público, como a exigência de aterros sanitários, parte da firmação de convênios com empresas privadas, em especial para os municípios brasileiros para que haja mudança no plano de gestão de resíduos sólidos de modo coerente ao que a legislação exige (Ferri et al., 2015).

A PNRS apresenta-se como um alicerce para o problema "lixo", e foi constituída com o objetivo de disciplinar, e legislar sobre eleja com a nomenclatura "resíduos sólidos". A estrutura que a compõe, está firmada em uma filosofia norteadora da prática e gestão deles, de modo coerente, geossistêmico e integrado, o que demonstra uma forma de planejamento e gestão à principal finalidade: proteger o meio ambiente, bem como os recursos naturais e as comunidades (Godoy, 2013).

Entretanto, desde a aprovação dela, o progresso quanto a aplicação, é lento no que diz respeito ao serviço de infraestrutura básica oferecido pelos municípios porque muitos ainda estão apenas na etapa de projetos-piloto, e por enquanto, observa-se que, alguns municípios já possuem a seletividade de seus resíduos (Ex.: Belém), grande parte da quantidade dos mesmos são enviados para os aterros, demonstrando então que a meta que fora estabelecida para agosto de 2014, onde o descarte para os aterros se tornariam apenas para os resíduos, não foi cumprida (Besen et al., 2014).

A NBR 10.004 (2004) estabelece que todo resíduo, em estados semissólido e sólidos, provenientes de atividades que possuem procedência em ambiente hospitalar ou doméstica, ou provenientes de comércios e indústria, de serviço ou de varrição, além do lodo que provém de tratamento de água, ou resíduos que são gerados de equipamentos e instalações necessitam de soluções e medidas técnicas, logo são de Classe: I perigosos; Classe IIA não perigosos e Classe IIB inertes (Figura 1).

Figura 1. Classificação de resíduos sólidos.

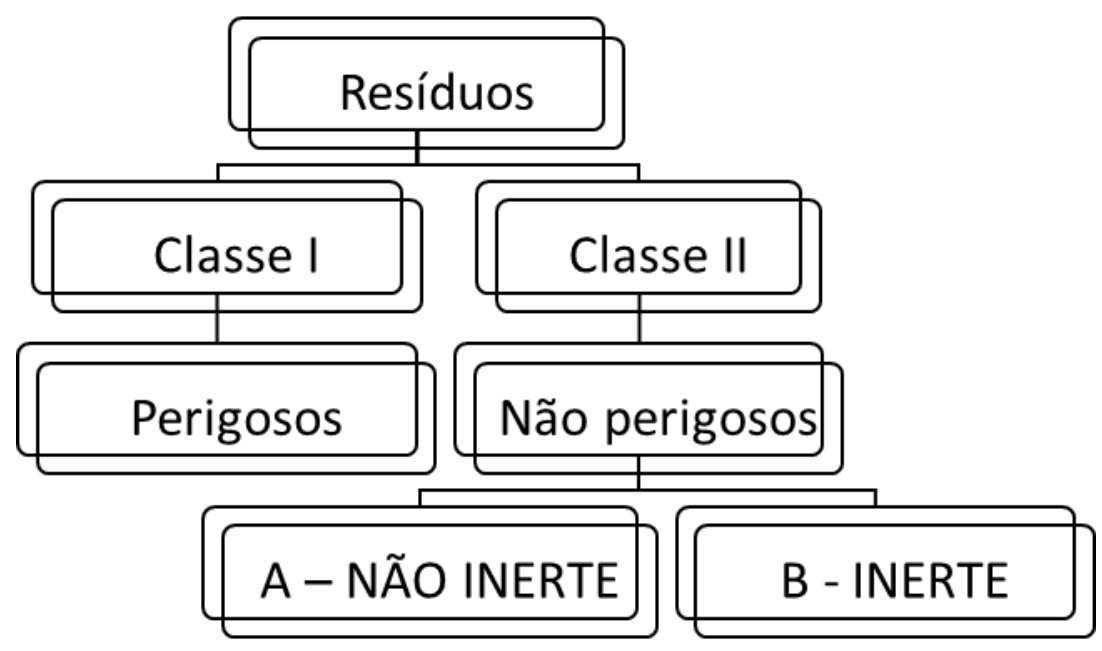

Fonte: Autores a partir de dados contidos na ABNT NBR 10.004 (2004).

\subsection{Coprodutos de resíduos de pescado e viabilidade de aplicação no Município de Marabá - Pará.}

$\mathrm{O}$ aproveitamento dos resíduos sólidos apresenta vários benefícios, como o aumento da vida útil dos aterros sanitários em consequência da diminuição da quantidade de resíduos que é destinada para esse local, consequentemente a conservação dos recursos naturais, prevenção a poluição, redução do desperdício, formação de novos produtos e subprodutos, geração de emprego e mão de obra (Santos et al., 2013). No que se refere a destinação final, o aterro sanitário é uma das alternativas utilizadas para a disposição dos resíduos sólidos, logo a degradação que ocorre nesse local resulta em subprodutos que, na maioria dos casos, em forma de Gás metano $\left(\mathrm{CH}_{4}\right)$ e lixiviado que são nocivos para o meio ambiente (Felici et al., 2013). 
Contudo, a aplicação de alternativas de aproveitamento dos resíduos de pescado tem como finalidade minimizar o descarte incorreto, o desperdício e reduzir os impactos ao meio ambiente, além de atribuir valor agregado a esta matéria-prima perecível que possui fonte nutricional para formulação de novos produtos (Silva et al., 2015). Logo, para os resíduos que são comestíveis e mais comercializados, como aparas de filetagem, espinhaço ou restos do processamento podem ser aproveitados para fabricação de outros produtos de baixo custo e com grande valor nutricional (Pinto et al., 2017).

\subsubsection{Fabricação de farinha para ração animal a partir de resíduos de pescado}

Os resíduos orgânicos de pescados podem ser usufruídos como ingredientes na fabricação de farinha, eles são submetidos ao processo de moagem e secagem. Esse produto pode ser aproveitado para alimentação animal, como ração, até mesmo retornando a cadeia produtiva da piscicultura, para a alimentação de peixes, sendo uma estratégia interessante e viável (Pires et al., 2014).

Em virtude de tais atributos podem ser transformado em diferentes subprodutos. Nesse sentido, o município de Marabá- Pará, encontra-se como um campo fértil para o aproveitamento de tal tipo de resíduo como ração na alimentação de peixes. Tendo em vista que, a região apresenta potencial para aplicação desse material, pois ela se destaca na prática dessa atividade. Além disso, levando em consideração suas características, também dispõe de expressivo número de produtores que fazem o emprego de áreas alagadas já existentes nas propriedades ou constrói pequenos lagos para criação de peixes para comercialização na região (Silva et al., 2010).

Nesse contexto, aplica-se o ciclo do Planejar, Executar, Controlar e Agir (Do inglês, Plan, Do, Control and Act PDCA, que é um método que permite atingir uma solução ao problema: os resíduos sólidos orgânicos (Lopes \& Alves, 2020), Dessa forma, é de fácil utilização como ingredientes na produção de ração para animais, por possuir alto teor de proteína, porém precisa serem processados de forma adequado pois é um composto de rápida decomposição. Alguns exemplos de resíduos de pescado que podem ser aproveitados para fabricação de farinha e utilizado na alimentação animal, são: as escamas, o esqueleto, carne e as vísceras (Lima, 2013).

Esses materiais apresentam um alto quantitativo de proteínas, fosforo e cálcio (Boscolo et al., 2012), Nesse contexto, podem ser utilizados, via método convencional, para a fabricação de farinha de peixe efetuado a partir da secagem dos resíduos ao ar livre ou seja, exposição ao sol, porém existem outros métodos, como a secagem a vácuo, todavia o custo é extremamente elevado (Higuchi, 2015).

\subsubsection{Adubo orgânico a partir de resíduos de pescado}

A adubação orgânica é uma técnica ambiental bastante usável e possuem facilidade no processo de metabolização devido as ações aeróbias de microrganismos contribuindo para os aspectos físico-químico do solo (Oliveira et al., 2018). O Município de Marabá - Pará, há a predominância do uso de adubação, a partir de adubos (químicos) e adubos orgânicos nas plantações. Ademais, a predominância da produção agrícola familiar na região se destaca por auxiliar na subsistência sendo uma forma de renda dos agricultores (Brito \& Mello, 2019).

Logo, a viabilidade do uso de resíduos de pescado aplicado para a produção de adubo orgânico nos processos de compostagem, é considerada uma alternativa eficiente (Valente et al., 2016). Pois, são compostos de proteínas, lipídeos, concentração nutricional elevada, ácidos graxos, ômega-3, carboidratos entre outros de alta importância biológico (Gonçalves, 2011). Se o local que gera o resíduo não possui tecnologia para tratar esse resíduo de modo diferenciado, sugere-se a compostagem orgânica como uma opção favorável (Vidotti \& Lopes, 2016).

No final tem-se um composto rico de uma mistura complexa, podendo ser disposto em solos sem causar prejuízo ao meio ambiente (Chiarelotto et al., 2018). Nesse sentido, o resíduo de pescado pode ser associado a casca esgotada de acácia, 
tem-se uma grande fonte de nutrientes para ser acrescidos como adubos e aplicados em produção de cultura agrícola familiar (Sanes et al., 2015).

\section{Material e métodos}

\subsection{Fisiografia do município}

A pesquisa foi desenvolvida no município de Marabá, situada na região sudeste do Estado do Pará onde a pesca é significativa e muito praticada, especialmente pela presença do Rio Tocantins e Itacaiúnas, considerada uma atividade extrativista tradicional e uma forma de subsistência da população na região (Oliveira et al., 2011). O delineamento da pesquisa foi aplicado em três feiras livres de comercialização de pescado do município, situadas no Núcleo Marabá Pioneira, Cidade Nova e Nova Marabá (Figura 2).

Figura 2. Mapa de Localização das feiras livres do município de Marabá - PA.

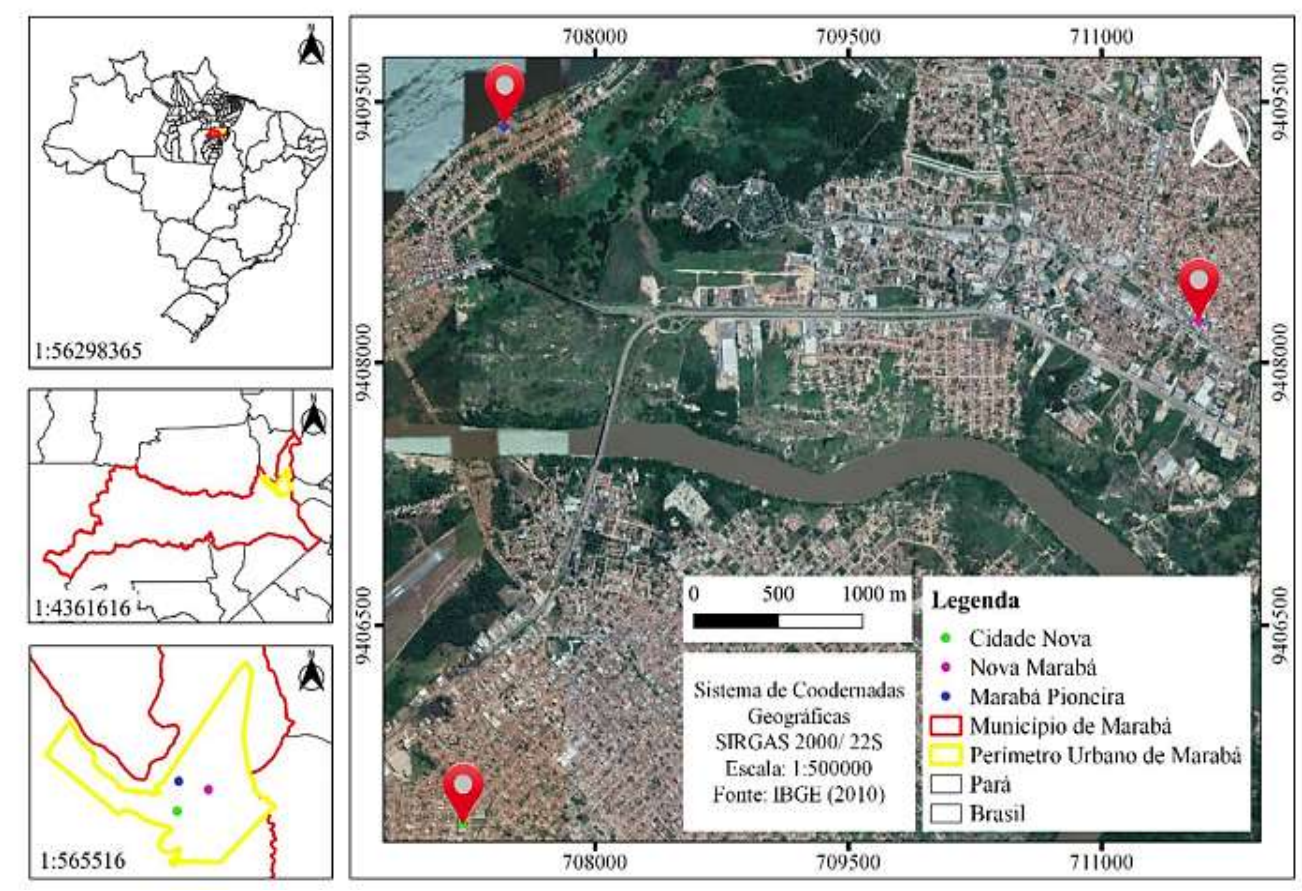

Fonte: Autores (2020).

A escolha das três feiras livres foi realizada em função das quantidades: 1) da comercialização do no pescado no município; 2) volume gerado de resíduos. Associou-se também a estrutura organizacional dos locais selecionados em que foi desenvolvido a pesquisa (Figura 3). 
Figura 3. Layout organizacional das feiras: 1 - Feira Colônia de Pescadores Z30, Travessa Zizi, núcleo Marabá Pioneira; 2 Feira Coberta Marabá, Av. Boa Esperança, Núcleo Cidade Nova; 3 - Feira da Folha 28, situado no núcleo Nova Marabá.

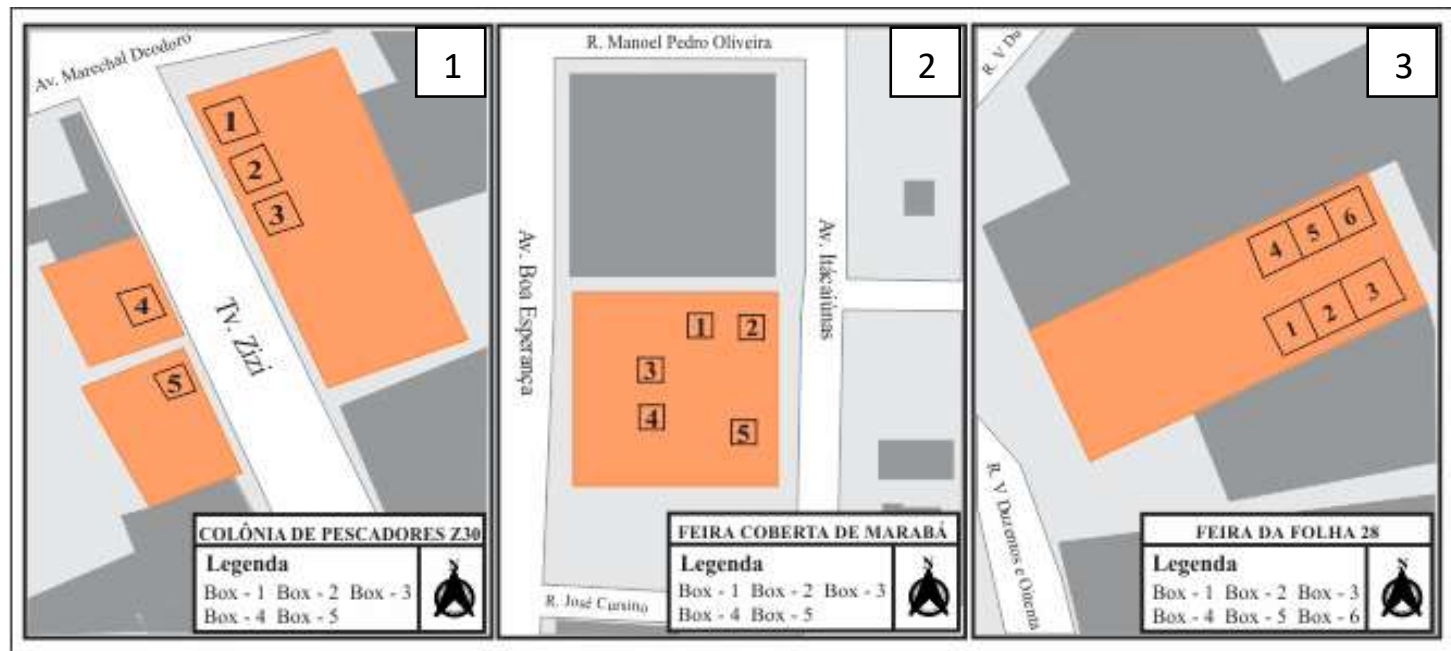

Fonte: Autores (2020).

\subsection{Método}

Essa pesquisa foi elaborada com base na argumentação efetuada sobre o método indutivo, Matias-Pereira (2016), sintetizou que se deve partir de um número suficiente de casos (Ex.: a maioria dos rios urbanos estão poluídos) para se chegar a uma conclusão verdadeira: a urbanização incrementa essa poluição. Pereira et al. (2018) explanam que o método estatístico estuda indivíduos (aqui, os peixeiros) com uma profissão (comerciantes), e que se pode verificar as condições ambientais no local onde labutam. Eles também afirmam que o quantitativo utiliza coletas de dados com o uso de medidas e números associados às respectivas unidades, cujos cálculos finais dos dados empregaram-se mecanismos matemáticos (Ex.: estatistica descritiva). Já o qualitativo, relaciona-se com o tipo de questões contidas no formulário que, nessa pesquisa, foram de caráter aberto, ainda de acordo com a explanação deles, os autores tornarem-se instrumentos de captação desses dados nos ambientes, o que de fato ocorreu nessa pesquisa, por isso, a abrangência tornou-se quantitativa e qualitativa.

\subsection{Dados Primários}

Foi feito um prévio levantamento prévio em cada feira sobre o número total de boxes e a quantidade de comerciantes atualmente, para se determinar a amostragem da população, com amostragem probabilística aleatória (Dias, 2018), que participaria da pesquisa. Para o cálculo amostral, foi utilizada a Equação 1.

$$
n=\frac{\mathrm{N} \cdot z^{2} \cdot p \cdot(1-p)}{(\mathrm{N}-1) e^{2}+z^{2} p(1-p)}
$$

Fonte: Barbetta (2002)

Onde: $n$ : Amostra calculada; N: População; Z: Variável normalmente padronizada, associada ao nível de confiança; $p$ : Verdadeira probabilidade do evento; e: Erro amostral.

Para Barbetta (2002), esse método serve para pesquisas sociais, devem ser diferenciadas "estratificada proporcional garante que cada elemento da população tem a mesma probabilidade de pertencer a amostra" e conter margem de erro. Dessa forma, para o erro amostral foi considerado $5 \%$ (Intervalo de confiança $=95 \%$ ) em relação ao verdadeiro valor do parâmetro 
que se anseia estimar. Com a aplicação do método proposto ele, para coleta de dados primários foram aplicados 36 formulários semiestruturados e composto por seis questões abertas (Figura 4)

Figura 4. Formulário elaborado e empregado para obtenção de dados, nas três feiras livres, acerca dos dados sociais e comerciais dos individuos amostrados. Marabá, Pará.

\begin{tabular}{|c|c|}
\hline \multicolumn{2}{|c|}{$\begin{array}{c}\text { Universidade do Estado do Pará } \\
\text { Centro de Ciências Naturais e Tecnologia } \\
\text { Laboratório de Qualidade Ambiental, Campus VI, Paragominas. } \\
\text { Departamento de Engenharia Ambiental e Sanitária } \\
\text { Campus VIII -Marabá }\end{array}$} \\
\hline Faixas etárias & Grau de escolaridade \\
\hline $\begin{array}{l}\text { ( ) } 18 \text { A } 28 \text { anos } \\
\text { ( ) } 29 \text { A } 39 \text { anos } \\
\text { ( ) } 39 \text { A } 49 \text { anos } \\
\text { ( ) } 50 \text { Anos } \\
\text { ( ) Mais de } 50 \text { anos }\end{array}$ & $\begin{array}{l}\text { ( ) Completo } \\
\text { ( ) Incompleto } \\
\text { ( ) Completo } \\
\text { ( ) Incompleto }\end{array}$ \\
\hline $\begin{array}{l}01 \text { - Quais os tipos de armazenamentos } \\
\text { utilizados na pré-venda no varejo, dos } \\
\text { pescados? } \\
02 \text { - Onde são armazenados os resíduos de } \\
\text { pescado feito no estabelecimento pós- } \\
\text { vendas? E na pós-vendas? } \\
03 \text { - Os resíduos orgânicos provenientes de } \\
\text { pescado são separados dos demais } \\
\text { resíduos comuns? }\end{array}$ & $\begin{array}{l}04 \text { - Qual o destino dos resíduos de pescado } \\
\text { gerado na feira? } \\
05 \text { - Você reconhece os impactos ao meio } \\
\text { ambiente que os resíduos orgânicos } \\
\text { ocasionam quando não gerenciado de } \\
\text { forma adequada? } \\
06 \text { - Você conhece alternativas sustentáveis } \\
\text { para a destinação final desses resíduos? } \\
\text { Se sim, quais? }\end{array}$ \\
\hline
\end{tabular}

Fonte: Autores (2020).

Prodanov e Freitas (2013) sintetizaram que o uso dessa ferramenta teve como objetivo coletar dados onde o pesquisador estabelece, elabora e anota previamente questões sobre tema desenvolvido. O formulário, estava acompanhado do Termo de Consentimento Livre e Esclarecido (TCLE), em atenção as Resoluções 466 (2012) e 510 (2016), que foi explicado ao participante, todo o contexto e aplicação junto ao número de individuos amostrados.

\subsubsection{Amostragem dos resíduos}

Os resíduos foram quantificados nas feiras livres, em cada box, ao final da comercialização no período matutino. Para a pesagem, foi utilizado uma balança digital portátil (marca WeiHeng) com capacidade de 50kg, no período de 30 dias (03/06/2019 a 02/07/2019). Essa ação foi realizada em duas etapas (Quadro 1). 
Research, Society and Development, v. 10, n. 4, e51310414417, 2021

(CC BY 4.0) | ISSN 2525-3409 | DOI: http://dx.doi.org/10.33448/rsd-v10i4.14417

Quadro 1. Etapas quanto à amostragem dos resíduos. Marabá - PA.

\begin{tabular}{|c|c|c|}
\hline Etapas & \multicolumn{1}{|c|}{ Ação } & Figuras \\
\hline 1 & os resíduos eram depositados em um balde revestido de um saco plástico & $5 \mathrm{a}$ \\
\hline 2 & o saco plástico era colocado no gancho da balança para pesagem & $5 \mathrm{~b}$ \\
\hline
\end{tabular}

Fonte: Autores (2020).

Figura 5. Resíduos orgânicos destinados à pesagem; b) Pesagem efetuada com balança de campo. Marabá Pará.

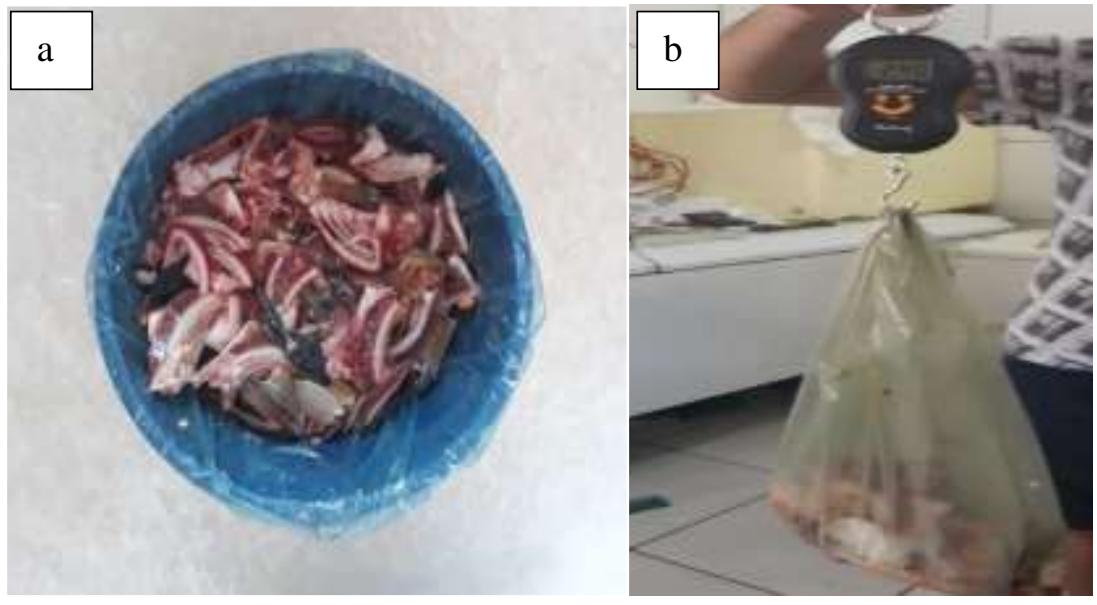

Fonte: Autores (2020).

Após a passagem os valores obtidos foram alocados em planilha de campo previamente elaborada para transferência, no Laboratório de Meio Ambiente, setor de informática, para análise estatistica (Figura 6). 
Figura 6. Modelo da planilha de campo utilizada para obtenção de dados sobre resíduos orgânicos gerados nas três feiras livres objetos dessa pesquisa. Marabá - Pará.

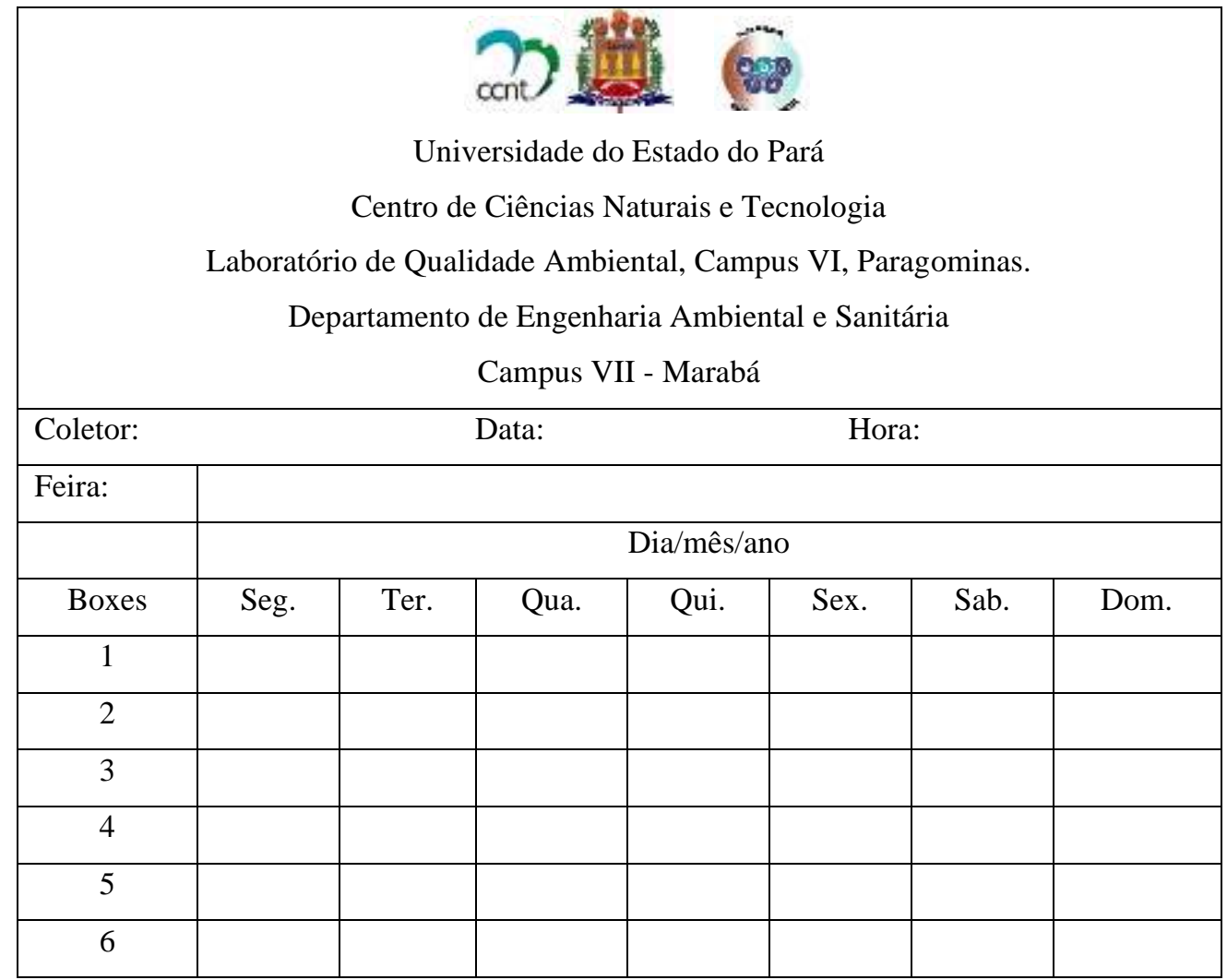

Legendas: Se. Segunda; Ter. Terça; Qua. Quarta; Qui. Quinta; Sex. Sexta; Sab. Sábado; Dom. Domingo. Fonte: Autores (2020).

A classificação do resíduo orgânico proveniente do pescado identificado nas três feiras livres foi realizada conforme preconiza a ABNT NBR 10004 (2004). Dessa forma, os resíduos são considerados Resíduos classe II A - Não inertes, que possui propriedades como biodegradabilidade, combustibilidade ou solubilidade em água. Para a apresentação e discussão dos dados obtidos adaptou-se aos resíduos orgânicos identificados, o descrito por Souza et al. (2019): 1) peles; 2) carcaça (cabeça e espinhaço; 3) Outros (barbatanas, brânquias, escamas, nadadeiras laterais, dorsais e caudais, e vísceras).

\subsection{Dados secundários}

O levantamento de dados documentais com recorte temporal compreendido entre 2010 e 2020, em links eletrônicos de acesso aberto como o Portal de Periódico da Coordenação de Aperfeiçoamento de Pessoal de Nível Superior (CAPES). Research, Society and Development, Science Direct, Scientific Electronic Library Online (SciELO) e WebScience. Foram priorizadas as literaturas publicadas nos últimos cinco anos (2016-2021) para obtenção de dados mais atualizados e excetuaram-se desse recorte, as legislações, nas três esferas políticas, além dos estudos pioneiros.

\subsection{Tratamento estatístico dos dados}

Os dados primários foram tratados estatisticamente com o uso de planilhas eletrônicas contidas no software Excel 2013 (MICROSOFT CORPORATION, 2016). Em seguida, aplicou-se para a Estatística Descritiva para cálculos das: frequências absoluta $(f i)$, relativa $(f r \%)$, média e desvio padrão $(\bar{x} \pm \sigma)$ Na sequência, foram confeccionados gráficos e tabelas para melhor exposição e interpretação dos resultados de acordo com o estabelecido pela normatização do Instituto Brasileiro de Geografia e Estatística (IBGE 1993). 


\section{Resultados e Discussão}

\subsection{Espécies de pescado comercializados}

A análise dos dados obtidos indicou que são comercializados atualmente nove espécies nas três feiras livres objetos dessa pesquisa. Dentre elas, as mais procuradas para consumo são: tambaqui e tucunaré (Quadro 2).

Quadro 2. Os nove tipos de peixes comercializados nas três feiras. Marabá - PA.

\begin{tabular}{|c|c|}
\hline Nome vernacular & Gêneros \\
\hline Barbado & Pinirampus $\mathrm{sp}$. \\
\hline Curimbatá ou curimatã & Prochilodus $\mathrm{spp}$ \\
\hline Mandi-mata & Pimelodus $\mathrm{sp}$ \\
\hline Pescada & Plagioscion $\mathrm{spp}$ \\
\hline Piabanha & Brycon $\mathrm{sp}$ \\
\hline Piramutaba & Brachyptalystoma \\
& vaillantii \\
\hline Tambaqui & Colossoma $\mathrm{sp}$ \\
\hline Tucunaré & Cichlais $\mathrm{spp}$ \\
\hline
\end{tabular}

Legendas: $f i$-frequência absoluta; $f \mathrm{r}(\%)$ - frequência relativa em porcentagem; $\bar{x}=$ média aritmética; $\sigma=$ desvio padrão. Fonte: Autores (2020).

O conhecimento dos peixes permite à Engenharia Ambiental e Sanitária, uma visão mais ampla quanto a geração de resíduos sólidos orgânicos como, por exemplo, barbatanas (Barbado), escamas (Curimatá), e assim identificar a fonte geradora dos ácidos orgânicos. Na pesquisa realizada por Rodrigues (2013), na colônia de pescadores Z3, Pelotas - RS, ela sintetizou que os resíduos orgânicos dispostos em locais inadequados como por exemplo, superfície do solo, a decomposição desse tipo de matéria gera gases impactantes ao meio ambiente (Ex.: $\left.\mathrm{CH}_{4}\right)$. Logo, o conhecimento dos resíduos orgânicos e de fonte geradora, pode auxiliar na prática de ações para evitar isso.

Sobre a diversidade de pescado na região Amazônica, Silva e Siebert (2019), efetuaram estudo no município de Santarém - PA sobre a diversidade na ictiofauna, e os dados que eles obtiveram, os permitiram afirmar que região Amazônica dispõe de ampla diversidade de peixes, e que aproximadamente 40 espécies podem ser encontrados nas feiras. Nas três feiras livres de Marabá, isso ocorreu com porcentagem equivalente a 22,5\% da quantidade indicada para Santarém.

\subsection{Quantidade comercializa em quatro semanas.}

A análise dos dados obtidos indicou que a quantidade de pescados vendidos nas três feiras objetos dessa pesquisa, o maior valor da média identificou a feira livre Coberta de Marabá, e o menor, identificou a segunda semana da Folha 28 (Tabela $1)$.

Tabela 1. Valores das médias de vendas de pescados durante quatro semanas, nas três feiras livres analisadas. Marabá, Pará.

\begin{tabular}{cccc}
\hline Semanas & $\mathbf{Z 3 0}$ & Coberta de Marabá & Folha 28 \\
\hline $\mathbf{1}^{\mathbf{a}}$ & $76,8 \pm 10,6$ & $88,8 \pm 9,2$ & $10,0 \pm 9,2$ \\
$\mathbf{2}^{\mathbf{a}}$ & $62,9 \pm 10,1$ & $117,3 \pm 12,3$ & $8,08 \pm 10,4$ \\
$\mathbf{3}^{\mathbf{a}}$ & $81,3 \pm 8,1$ & $7,4 \pm 5,0$ & $16,5 \pm 8,5$ \\
$\mathbf{4}^{\mathbf{a}}$ & $86,2 \pm 8,7$ & $55,7 \pm 6,3$ & $9,6, \pm 6,0$ \\
\hline
\end{tabular}

Fonte: Autores (2020). 
Quanto ao volume de pescados comercializados em feiras livres, a pesquisa feita por Jesus et al. (2018) sobre os aspectos da comercialização de pescado em feiras livres do município de Feira de Santana - BA, demonstrou que os valores recorrentes de venda ficaram em torno de $550 \mathrm{~kg}$ a $800 \mathrm{~kg}$ por banca, constatou-se ainda bancas com vendas entre $850 \mathrm{~kg}$ e $1000 \mathrm{~kg}$, como também, barracas com valores de $200 \mathrm{~kg}$, valores esses obtidos semanalmente. Já em Cruz das Almas - BA, Barreto et al. (2012) efetuaram um estudo no mercado municipal daquele município, e concluíram que o volume de peixe comercializado varia de 50 a $1000 \mathrm{~kg} / \mathrm{semana}$.

Na pesquisa realizada no município de Santos - SP, por Santos (2016) na maior região pesqueira da região metropolitana da Baixada Santista, ele obteve dados que o permitiu afirmar que os principais centros de comércio de pescado do munícipio são o mercado do peixe e a rua do peixe, geram, em média, 23,6 t semanais de resíduos. Em Maraba, os valores acumulados, em kg, nas quatro semanas foram: $\mathrm{Z} 30=1.536,3$; Coberta de Marabá $=1.560,6$ e Folha $28=2.114,9$. Logo, a comercialização foi mais efetiva em Marabá, o que induz a um maior volume parda os resíduos sólidos orgânicos.

\subsection{Resíduos orgânicos: Tipos, quantificação}

Os dados obtidos e analisados indicaram que na Z30, o resíduo do tipo 3, foi o de maior produção $(88,4 \pm 21,6)$, seguida pela Feira Coberta de Marabá com o tipo $1(77,4 \pm 0,0)$, quando comparado com os valores das médias entre eles (Tabela 2).

Tabela 2. Os tipos de resíduos gerados durante a comercialização no varejo, dos pescados por feiras. Marabá - PA.

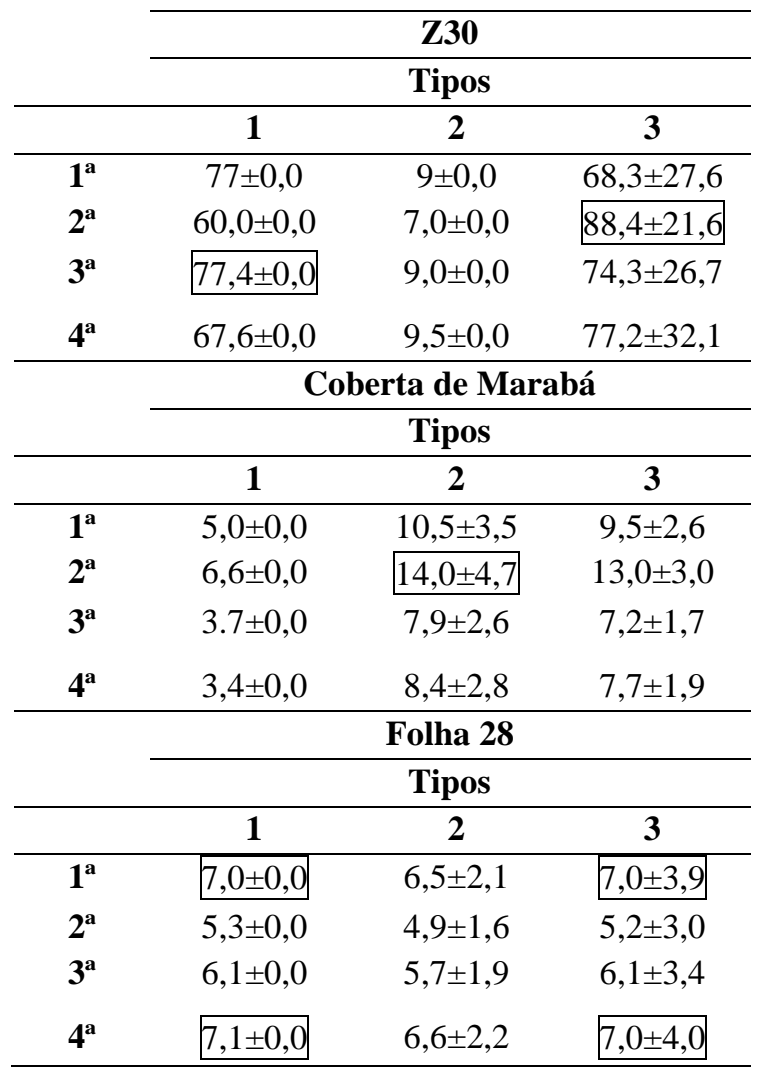

Legendas: Tipo 1: pele; Tipo 2: carcaça (cabeça e espinhaço; Tipo 3: outros (barbatanas, escamas, nadadeiras dorsais, laterais e caudais, e vísceras). Fonte: Autores (2020).

Os dados obtidos e analisados indicaram uma produção de residuos orgânicos, a feira livre Z30, gerou maior quantidade do Tipo 3; A coberta de Marabá, o tipo 2, e a feira livre Folha 28, gerou o tipo 1 e 3. O Tipo 3, tem os componentes, as visceras, e ocorreu em todas as férias objetos dessa análise, isso ocorreu porque o consumidor pede ao 
vendedor que prova evisceramento, a descamação, o corte das barbatanas e nadadeiras. Acerca desses resíduos, Souza et al. (2019) realizaram estudo no mercado municipal do Ver-o-Peso, e concluiram: quando o evisceramento é efetuado no barco fornecedor do pescado, ele diminui a quantidade nos resíduos das feiras.

Quanto as vísceras, em Marabá, a quantidade acumulada, em $\mathrm{kg} / \mathrm{mês}$, foi menor ( $n=180,6 ; 13,5 \%$ ), quando comparado aos demais componentes do tipo 3: escamas $(n=423,1 ; 31,6 \%)$, barbatanas $(n=415,1 ; 31 \%, 0)$; nadadeiras $(n=$ $320,6 ; 22,9 \%)$. os valores mostraram que isso não ocorreu, por isso, apresentou os maiores valores em média.

Acerca desses tipos de resíduos, foi realizada uma pesquisa na cidade de Manaus - AM, Universidade Nilton Lins, por Nascimento et al. (2018). Os dados que eles obtiveram, indicaram que, dentro da cadeia produtiva da indústria pesqueira, os descartes de cabeças, vísceras e escamas e carcaças (esqueleto com resíduo de carne) pode representar algo em torno de $8 \%$ a 16\% (sendo pescado eviscerado), e 60 a 70\% na produção de filés sem pele, dependendo da espécie de peixe processado e do produto final obtido por mercados e feiras.

Sobre as carcaças (cabeça e espinhaço), nas três feiras livres objetos dessa pesquisa, a análise dos dados obtidos indicou que foram produzidas $197,5 \mathrm{~kg} / \mathrm{mês}$, e mais prolífera foi a feira Coberta de Maraba ( $n=81,9 \mathrm{~kg} / \mathrm{mês} ; 41,2 \%)$, em seguida, Z30 ( $n=69,0 \mathrm{~kg} / \mathrm{mês} ; 39,4 \%)$ e a da Folha 28 ( $n=47,1 \mathrm{~kg} / \mathrm{mês} ; 23,8 \%)$. No estudo efetuado em Manaus, os dados indicaram que as carcaças resultam da extração da massa corporal para a produção do filé de peixe, porém em Marabá, a produção mensal de espinhaço foi quase a metade do total produzido para o tipo 2 ( $n=83,5 \mathrm{~kg} / \mathrm{mês} ; 42,25)$, $\operatorname{logo}$, abaixo do encontrado em Manaus (60\% a 70\%). Então, nas feiras livres de Marabá, a produção do filé de peixe, não é frequente.

\subsection{Acondicionamento externo e coleta}

No caso das feiras livres de Marabá, so resíduos orgânicos são acumulados na parte latero-posterior dos boxes onde ocorrem as vendas e, ao decomporem liberam, além da tri-metil-amina $\left(\mathrm{C}_{3} \mathrm{H}_{9} \mathrm{~N}\right)$, o metano $\left(\mathrm{CH}_{4}\right)$ e ambos provocam odor esteticamente desagradável aos consumidores como podem incrementar o risco de contaminação dos produtos ali comercializados. A coleta é realizada pela equipe de agentes de limpeza do serviço público que os coloca no interior de caminhões compactadores do Serviço de Saneamento Ambiental Marabá (SSAM), e conduzidos ao aterro controlado do município.

Em relação ao serviço de coleta em feiras livres, houve uma pesquisa realizada na Feira Livre 8 de Maio, no Distrito Administrativo de Icoaraci em Belém - PA, Raiol et al. (2019), e os dados que eles obtiveram os permitiu afirmar que grande parte dos feirantes colocam os resíduos armazenados em frente aos postos de trabalho ao invés de colocarem em locais específicos para a coleta. Nas três feiras livres de Marabá, esse local não foi observado.

A pesquisa feita por Santos et al. (2013) sobre a avaliação das condições higiênico-sanitárias da feira livre da colônia dos pescadores no município de Uruçuí - PI identificou que além da falta de infraestrutura identificados, o acúmulo dos resíduos de pescado causa desconforto, contaminação e odores desagradáveis.

Sobre essa geração causada pelos resíduos sólidos orgânicos, Cândido e Meira (2017) efetuaram estudo na feira livre de Caldas Novas - MG, e concluiram que não existe um plano de gerenciamento para esses materiais, e que eles se encontravam "misturados" mas sem estar acondicionado de forma correta. Nas Três feiras livres de Marabá, estas características todas foram identificadas, o que corrobora com o descrito em Caldas Novas.

4.5 Condições higiênico-sanitárias no setor de pescados

Nos 28 dias de pesquisa ocorrida nas três feiras livres pesquisadas, verificou-se que, em termos higiênicos-sanitários descritos na e Portaria n. 326 (1997), o setor de comercialização de pescados onde o armazenamento temporário dos resíduos orgânicos está inadequado, tanto na parte interna quanto na parte externa. Os manipuladores (peixeiros) não utilizam equipamentos adequados como, por exemplo, tocas, máscaras, luvas, dentre outros. 
Foi observado também a frequência de animais como cães (Canis spp.) e gatos (Felis catus Linnaeus, 1758), a procura de alimentos, que os retiram dos baldes e cestos de lixos destampados, ou recebem dos próprios peixeiros que, com o objetivo de afastá-los, atiram ao chão e um pouco distante do box, brânquias e vísceras. A lavagem dos pescados é efetuada em tanques com revestimento cerâmico extremamente deficiente e com vazamentos nas áreas externas, contendo escamas, sangue, dentre outros tios de resíduos.

Sobre esses fatos, Matos et al. (2015) efetuaram uma revisão integrativa acerca das condições higiênico-sanitárias em feiras livres, e concluiram que elas não oferecem condições higiênico-sanitárias que possam evitar impactos sobre a saúde dos consumidores. Já em Macapá - AP, Mota et al. (2020), realizaram pesquisa nas feiras urbanas daquele município e concluiram que os maiores problemas estão relacionados a estrutura, geração e descarte de resíduos. Em Marabá, isso foi notório e comprometeu as condições higiênico-sanitárias das três feiras analisadas.

\subsection{Percepção ambiental dos indivíduos amostrados}

\subsubsection{Amostragem da população}

Os dados obtidos e analisados para os indivíduos amostrados indicaram que em duas das três feiras, o número deles foi similar. Isso porque ambas são arquiteturas mais antigas e a estrutura interna oferta menor quantidade de boxes. Já para feira Coberta, a área é maior (Tabela 3).

Tabela 3. Número total de formulários a serem aplicados de acordo com número de boxes e comerciantes em cada feira livre. Marabá - PA.

\begin{tabular}{ccc}
\hline Feiras Livres & $\mathrm{N}^{\circ}$ boxes & $\mathrm{N}^{\circ}$ comerciantes \\
\hline Colônia Z30 & 5.0 & 11.0 \\
Feira Coberta Marabá & 5.0 & 13.0 \\
Folha 28 & 6.0 & 12.0 \\
\hline Total de formulários & 16.0 & 36.0 \\
\hline
\end{tabular}

Fonte: Autores (2020).

Acerca da amostragem quanto ao tamanho, Patino e Ferreira (2016), escreveram que o efeito da intervenção sobre o problema determina menor ou maior necessidade do tamanho amostrado, pois quanto menor for o tamanho e maio for o efeito da intervenção, melhor será a comprovação desse resultado. Em Marabá, buscou-se entendê-los, tanto nos peixeiros, quanto nos frequentadores e alimentos ali expostos, por isso o número amostral foi satisfatório para obtenção das informações necessárias às discussões sobre essas relações.

\subsubsection{Perfil social}

Os dados obtidos a partir da aplicação dos 36 formulários aos comerciantes de pescados das três feiras estudadas indicaram o perfil social dos indivíduos amostrados, como faixa etária e o grau de escolaridade. Dessa forma, na feira Z30 ( $n=$ $6,0 ; 54,5 \%)$ e Feira coberta de Marabá $(n=6,0 ; 46,1 \%)$, a faixa etária predominante situou-se entre 29 e 39 anos, Já a feira Coberta de Marabá $(n=6,0 ; 41,6 \%)$ apresentou elevação dessa faixa: 39 a 49 anos (Tabela 4). 
Tabela 4. Identificação social dos comerciantes das feiras analisadas. Marabá - PA.

\begin{tabular}{ccccccc}
\hline Variáveis & \multicolumn{2}{c}{ Z30 } & \multicolumn{2}{c}{ Coberta de Marabá } & \multicolumn{2}{c}{ Folha 28 } \\
\hline Idade & $\mathrm{fi}$ & $\mathrm{fr}(\%)$ & $\mathrm{fi}$ & $\mathrm{fr}(\%)$ & $\mathrm{fi}$ & $\mathrm{fr}(\%)$ \\
\hline 18 a 28 anos & 2.0 & 18,1 & 2.0 & 15,3 & 2.0 & 16,6 \\
29 a 39 anos & 6.0 & 54,5 & 5.0 & 38,4 & 4.0 & 33,3 \\
39 a 49 anos & 2.0 & 18,1 & 6.0 & 46,1 & 5.0 & 41,6 \\
50 anos & 1.0 & 9,0 & 0.0 & 0.0 & 1.0 & 8,3 \\
& 11 & \multicolumn{2}{c}{13} & & 12 & \\
\hline & $\mathrm{Z} 30$ & \multicolumn{2}{c}{ Coberta de Marabá } & \multicolumn{2}{c}{ Folha 28 } \\
\hline Escolaridade & $\mathrm{fi}$ & $\mathrm{fr}(\%)$ & $\mathrm{fi}$ & $\mathrm{fr}(\%)$ & $\mathrm{fi}$ & $\mathrm{fr}(\%)$ \\
\hline E.F.C & 4.0 & 36,3 & 5,0 & 38,4 & 1.0 & 8,3 \\
E.F.I. & 2.0 & 18,1 & 3,0 & 23,0 & 2.0 & 16,6 \\
E. M. C. & 5.0 & 45,4 & 4,0 & 30,7 & 6.0 & 50.0 \\
E.M.I. & 0.0 & 0.0 & 1,0 & 7,6 & 3.0 & 25.0 \\
& 11 & & 13 & & 12 & \\
\hline
\end{tabular}

Legendas: fi -frequência absoluta; fr $(\%)$ - frequência relativa em porcentagem; ${ }^{\bar{x}}=$ média aritmética. ${ }^{\sigma}=$ desvio padrão; EFC - ensino fundamental completo; EFI - ensino fundamental incompleto; EMC - ensino médio completo; EMI - ensino médio incompleto. Fonte: Autores (2020).

Para o grau de escolaridade, a análise dos dados indicou que a maioria dos feirantes $(5,0 \pm 1,0)$, possui o ensino médio completo. Sobre a escolaridade, Mota et al. (2020), efetuaram estudo em Macapá - AP, e concluiram, quanto grau de escolaridade dos feirantes de peixes, que a maioria deles não concluiu o ensino fundamental devido ingresso no mercado de trabalho em tenra idade. Em Marabá, isso não foi evidenciado, já que os dados obtidos indicaram que uma grande parte deles, possuem o fundamental completo $(3,3 \pm 2,1)$. Isso pode ser explicado pelas retrações do mercado de trabalho em função da pouca oferta de emprego e a necessidade de prover o sustento familiar.

Os dados obtidos e analisados indicaram que os "peixeiros" podem ser classificados como uma "comunidade de prática", ou seja, um grupo informal que estão interligadas pela partilha do conhecimento. No caso desses feirantes, a interligação ocorre na manutenção, distribuição geográfica e econômica que a feira livre representa, por isso, ao abordá-los, torna-se mais fácil conhecer o problema a ser discutido.

Outro fato que se pode analisar quanto ao social dos participantes, é que eles percebem o ambiente e, consequentemente os problemas neles contidos como, por exemplo, acúmulo de resíduos de peixes na feira livre, os atinge de alguma forma. Nesse aspecto Gibaldi et al. (2020)., realizaram uma pesquisa no Parque Natural Municipal Chico Mendes - RJ, e concluiram que quanto maior o grau de escolaridade, maior e o descaso com o meio ambiente. Logo, os feirantes que comercializam pescados mostraram-se preocupados com a situação atual dos resíduos sólidos nas feiras onde atuam. Então a importância da participação deles nessa pesquisa, elevou-se.

\section{5.3 Compilação de dados obtidos - formulários}

\section{Questão 1: Sobre armazenamento pré-venda e Questão 2: Resíduos pós-vendas.}

Para essa etapa, os dados obtidos e analisados indicaram que todos on indivíduos amostrados $(n=36 ; 100 \%)$ utilizam, na pré-venda, caixas de estireno expandido, denominado popularmente de isopor (Figura 7a) nas três feiras. A geração residual inicia, quando ocorre o corte, que se difere em três momentos (dependendo da espécie comercializada e a 
pedido do comprador): descamação, evisceração (Figura 7b) e/ou filetagem. Em relação ao armazenamento temporário dos resíduos orgânicos gerados pós-vendas, indicaram que a maioria deles $(8,3 \pm 1,5)$ utilizam baldes plásticos de $5 \mathrm{~L}$; sacos plásticos de cor preta/cinza de $100 \mathrm{~L}(2,3 \pm 1,5)$; tambores/bombonas de $50 \mathrm{~L}(1,0 \pm 1,0)$ sem tampa, e balde (Figura $7 \mathrm{c}$ ) forrada com saco plástico de $5 \mathrm{~L}(0,3 \pm 0,6)$.

Figura 7. a) Peixe submerso em gelo dispostos em caixa de isopor; b) Comerciantes e o processo de evisceração; c) Resíduos sem segregação depositados em baldes. Box 01 - Feira Coberta de Marabá, núcleo Cidade Nova. Marabá, Pará, Brasil

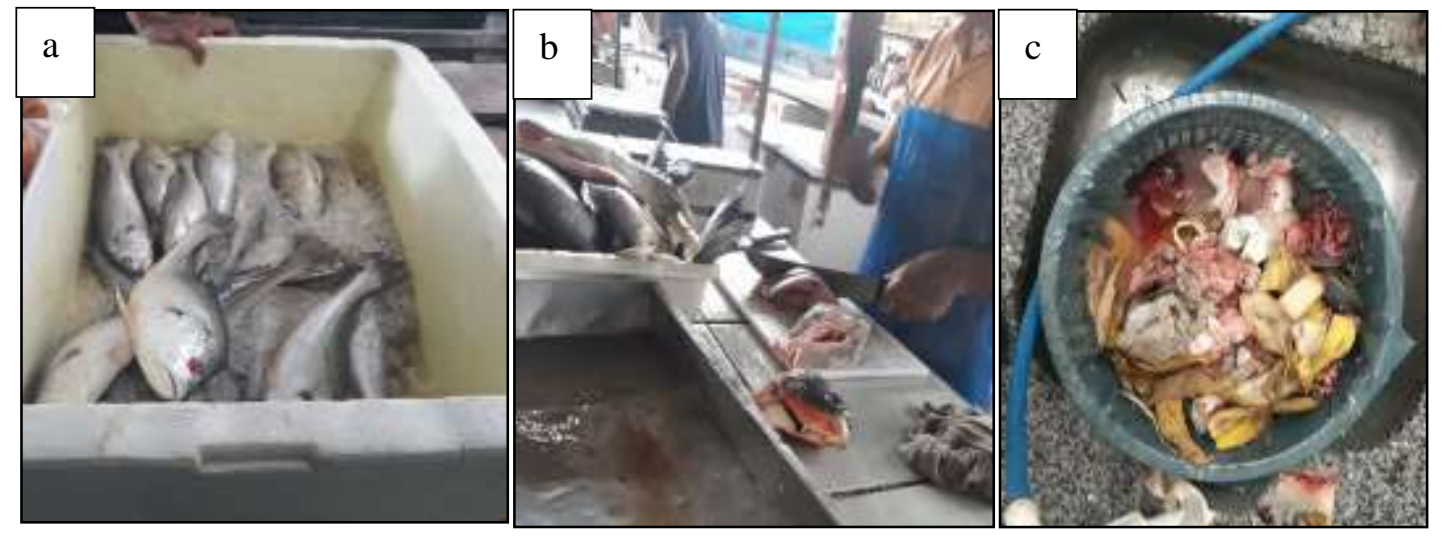

Fonte: Autores (2020).

$\mathrm{Na}$ análise individual das feiras livres pesquisadas, a Coberta de Maraba, apresentou maior número de usuários para o balde ( $n=9,0 ; 25 \%$ ), já em Z30 e Feira da 28 o uso dele tem a menor frequência $(n=8,0 ; 22,2 \%)$. O acondicionamento incorreto deixa os resíduos de pescados expostos. Além disso, notou-se a presença de outros tipos de resíduos nos coletores dos resíduos orgânicos improvisados. Em consequência disso, já havia a presença de insetos (Ex.: Musca spp.) e odores em consequência da liberação de gases do processo de decomposição da matéria prima (Ex.: CH4), bem como da tri-metil-amina $\left(\mathrm{C}_{3} \mathrm{H}_{9} \mathrm{~N}\right)$.

Quanto a essas ações, por Cunha et al.(2013) efetuou estudo na cidade de Manaus - AM, e concluiu que as condições higiênico-sanitárias do pescado varia de moderado a alto porque há presença de invertebrados transmissores de doenças à população do entorno e aos trabalhadores como efeito da presença de resíduos em locais inadequados. Todos esses fatos foram comprovados em Marabá. Portanto, no quesito acondicionamento não obedece aos padrões estipulados pela Resolução CONAMA n. 275 (2001) que, dentre várias exigências, determina que o local dessa ação, seja arejado, acondicionado em recipiente com identificação, com as cores padronizadas nela.

\section{Questão 3: Segregação dos resíduos}

$\mathrm{Na}$ análise dos dados obtidos para essa questão, constatou-se que a maioria dos indivíduos amostrados $(6,7 \pm 3,1)$, não pratica a segregação residual, todavia, ele é praticado pela minoria $(5,3 \pm 2,5)$. Outra constatação foi quanto a prática dessa ação entre as três feiras pesquisadas. Nesse caso, tanto em Z30 ( $\mathrm{n}=9,0 ; 25 \%)$; quanto na Feira Coberta $(n=7,0 ; 19,4 \%)$, os comerciantes que não praticam a segregação, são a maioria, porém na Feira da Folha 28, isso se inverteu $(n=8,0: 22,2)$.

Na revisão bibliográfica efetuada por Silva et al. (2015), escreveram que esse tipo de lixo, a segregação pode permitir um reaproveitamento desses resíduos porque quando se separam os de peixes de outros, pode-se gerar novos produtos e agregar valores a eles. Outro fator que pode conduzir a não segregação pelos feirantes que comercializam pescados, é a falta de estrutura adequada para prática dessa ação. Sobre isso, Jesus et al. (2018) efetuaram estudo em Feira de Santana - BA, e concluiram que a manutenção e a adaptação dos espaços físicos das feiras livres são de responsabilidade do poder público. 
Com base nisso, pode-se afirmar que esse poder está ausente ou possui atuação ineficaz, tanto na melhoria da infraestrutura, quanto na capacitação dos comerciantes de peixes para segregação adequada dos resíduos gerados pós-vendas.

\section{Questão 4: Sobre a destinação dos resíduos de pescado}

Os dados obtidos e analisados indicaram que todos os individuos amostrados $(n=36: 100 \%)$, sabem que os resíduos sólidos coletados nas três feiras, tem como destino final o aterro controlado do município. Sobre essa disposição final, Mendonça et al. (2017), em revisão de literatura sobre esse assunto, afirmaram que após a cobertura deles por uma camada de terra, não elimina o risco de poluição das águas subterrâneas e contaminação do solo se houver proliferação de bactérias patogênicas, especialmente no período chuvoso, onde haverá infiltração e percolação da água pluvial e consequente formação do chorume.

Já a pesquisa realizada por Carvalho et al. (2019), sobre geração e coleta de resíduos sólidos urbanos em Marabá, Pará, os autores concluiram que os resíduos orgânicos representam a maior parcela (50\% a 60\%) deles, e uma das alternativas para mitigar os impactos ambientais no aterro controlado pode ser a compostagem.

\section{Questão 5: Conhecimento acerca dos impactos ambientais}

Para esse tipo de conhecimento a partir dos indivíduos amostrados, que a maioria deles desconhece esse fato $(7,0 \pm 2,0)$. Todavia, há, dentre eles, aqueles que tem conhecimento de danos que o descarte inadequado causa ao ambiente $(5,0 \pm 1,7)$. Na análise de cada local pesquisado, verificou-se que a feira coberta de Marabá, possui o grupo de comerciantes que conhecem sobre esse assunto $(n=9,0 ; 69,2 \%)$, já em Z30 e Folha 28, há uma similaridade quanto a ao número de conhecedores dos impactos $(n=4,0 ; 36,3 \%)$.

O desconhecimento quanto a impactos ambientais causados por resíduos sólidos, está atrelada ao não cumprimento da responsabilidade social, além de uma capacitação eficaz para saber como descartar de forma correta o RS por eles gerados. Este tema já foi objeto de pesquisa Costa e Souza (2012), em Parintins - AM. Eles concluiram que os autores envolvidos não foram submetidos a um curso de capacitação e que somente o conhecimento não é suficiente. Em Marabá, constatou-se que esse último, ocorre, porém a prática dela não foi evidenciada.

\section{Questão 6: Conhecimento de alternativas sustentáveis para os RS}

Indagados sobre quais se conheciam alternativas para aplicação dos resíduos orgânicos por eles produzidos, grande parte deles $(\mathrm{n}=11 ; 35,5)$, e a maioria desconhece $(\mathrm{n}=25 ; 69,4)$. Logo após lhes foi perguntado qual a alternativa que conheciam: 1) produção de ração animal $(5,0 \pm 2,7)$ e 2) adubo orgânico $(2,0 \pm 3,1)$.

Sobre essas alternativas, Na pesquisa realizada em Aracajú - SE, por Bery et al. (2012), os dados que esses autores obtiveram os permitiram escrever que os resíduos de pescados podem ser modificados e transformados em silagem, óleos de peixe, farinhas, ou até mesmo biodiesel, e outros subprodutos fermentados. Já o estudo efetuado no município de Pelotas - RS, por Decker et al. (2016), concluiu que, a partir das análises físico-químicas e microbianas dos resíduos de pescados, o uso deles como fertilizantes do solo, pois são altamente biodegradáveis.

A pesquisa realizada por Nascimento et al. (2018), no município de Manaus - AM, sobre a avaliação e caracterização do processo de compostagem de resíduos de peixes, foi conclusiva quanto a produção de um composto a partir da compostagem, como uma forma ambientalmente correta para o aproveitamento de resíduos de peixe e em consonância com a legislação a respeito dos valores de carbono e nitrogênio permitidos para o uso de fertilizantes orgânicos. 


\subsubsection{Sugestões ambientais para o resíduo de pescado identificado nas três feiras livres. Marabá (PA).}

1) Capacitação dos feirantes quanto ao armazenamento adequado do pescado a ser comercializado, a partir da construção de uma câmara fria na parte posterior das feiras que ficará sob gestão do administrador desses locais.

2) Construção de caneletas receptoras à frente dos boxes, cobertas, e com substâncias desinfetantes como o cloro. Recepção em fossa séptica para A água da lavagem dos pescados, após o tratamento básico em filtros com tubos de poliacrilato de vinila (PVC) de $100 \mathrm{~mm}$, contendo no interior, 1/3 de caroço de açai (Euterpe oleracea Mart.) sob a forma de carvão ativado, 1/3 de seixo médio e, por último, 1/3 de areia fina. Ao final da depuração ela seria utilizada para lavagem dos locais ao final do dia de trabalho.

3) Implantação de coletores seletivos em obediência à Resolução CONAMA 275 (2001). A confecção deles poderá ser efetuada com material reciclável, conforme foi demonstrado na pesquisa efetuada em Paragominas - PA, por Conceição e Pereira Júnior (2020). A mão de obra para tal pode ser ofertada pela própria comunidade que labuta nas três feiras.

4) Prática de compostagem com os resíduos orgânicos tipos 1,2 e 3. O espinhaço poderá gerar ração animal. Estudos acerca disso (Adame, 2014; Oliveira et al., 2012; Sanes et al., 2015), consideraram o alto valor nutricional, o volume de resíduo descartado de pescado para adubação do solo.

\section{Conclusão}

Atualmente, são comercializados nove gêneros de pescados, nas três feiras livres, um total de $5.200 \mathrm{~kg}$, que são acondicionados de forma inadequada, tanto nos 16 boxes onde ocorrem as vendas, como no armazenamento temporário à espera da coleta seletiva realizada pela prefeitura local. A água de lavagem é dispersa pelo piso tanto box quanto da feira. É frequente a presença de vertebrados como, cães e gatos, bem como de invertebrados como as moscas, o que obriga os feirantes e consumidores a estarem abanando as mãos para dispersarem esses animais. Isso eleva os fatores de risco de contaminação tanto dos alimentos quanto dos feirantes e compradores.

A percepção ambiental dos feirantes é evidente quanto aos riscos ambientais e da qualidade de vida que a destinação e disposição final inadequada dos resíduos de peixes podem causar, embora tenham demonstrado conhecer algumas alternativas para o reaproveitamento desses resíduos.

Recomenda-se que haja mais pesquisas tanto para o monitoramento dos resíduos sólidos orgânicos ali produzidos quanto uma adequação ao armazenamento temporário deles e da água de lavagem, o que tornará o espaço de comercialização dos pescados menos contaminante com elevação das condições higiênico-sanitárias, logo, adequação às normas legislativas de comercialização e ambientais brasileiras, maior frequência da comunidade, maior volume de vendas, maior quantidade de resíduos a serem coletadas e maior será a produção do adubo orgânico e maior será o incremento à agricultura natural.

\section{Referências}

Adame, C. R. (2014) Utilização de composto orgânico de peixe em adubação de capim-marandu. (Dissertação de mestrado). Universidade Estadual Paulista. https://repositorio.unesp.br/handle/11449/115951

ABNT NBR n. ${ }^{\circ}$ 10004, de 31 de maio de 2004. Esta Norma classifica os resíduos sólidos quanto aos seus riscos potenciais ao meio ambiente e à saúde pública, para que possam ser gerenciados adequadamente. https://www.abntcatalogo.com.br/norma.aspx?ID=936

Amorim, R.G.O. (2014). Hidrolisado proteico dos resíduos de corvina (Micropogonias furnieri) como forma de agregar valor ao pescado e reduzir o passivo ambiental das indústrias de pesca no município de Itajaí - SC. (Dissertação de Mestrado). Universidade do Vale do Itajaí. Santa Catarina, SC, Brasil. http://siaibib01.univali.br/pdf/Ricardo\%20Gaya\%20Oliveira\%20de\%20Amorim.pdf

Barbetta, P. A. (2002). Estatística aplicada às Ciências Sociais. (5a ed). Santa Catarina: UFSC,

Barreto, N. S. E., Moura, F. C. M., Teixeira, J, A., Assim, D. A., \& Miranda, P. C. (2012). Avaliação das condições higiênico sanitárias do pescado comercializado no município de Cruz das Almas, Bahia. Revista Caatinga, 25(3),86-95. https://periodicos.ufersa.ed u.br/index.php/caatinga/article/view/2209/pdf_14 
Bendito, B.P.C., Souza, P. A., Picanço, A. P., Silva, R, R, \& Sciebeneichier, S. (2017). Diagnóstico da degradação ambiental na área de deposito inadequado de resíduos sólidos de Porto Nacional - TO. Revista Gaia Scientia, 11(3), 129-151. Iperiodicos.ufpb.br/index.php/gaia/article/view/29908. http://doi.org/10.22478/ufpb.1981-1268.2017v11n3.29909

Bery, C.C.S. (2012). Estudo da viabilidade do óleo de vísceras de peixes marinhos ((Seriola Dumerlii (Arabaiana), Thunnus ssp (ATUM), Scomberomorus cavala (Cavala) e Carcharrhinus spp (Cação)) Comercializados Em Aracajú-SE para a produção de biodiesel. Revista Geintec, 2(3), 297-306. http://dx.doi.or/10.7198/S2237-0722201200030009

Besen, G. R., Ribeiro, H., Gunther, W. M. R., \& Jacobi, P. R. (2014). Selective waste collection in the São Paulo metropolitan region impacts of the national solid waste policy. Revista Ambiente \& Sociedade, 17(3), 253-272. https://www.scielo.br/pdf/asoc/v17n3/en_v17n3a15.pdf. https://doi.org/10.1590/S1414$753 \times 2014000300015$

Boscolo, W. R. (2012). Sistema orgânico de produção de pescado de água doce. Revista Brasileira de Saúde e Produção Animal, (2), 578-590. https://www.scielo.br/pdf/rbspa/v13n2/a25v13n2.pdf. http://dx.doi.org/10.1590*S1519-99402012000200025.

Brito, M. A., \& Mello, A.H. (2019). Diversificação da produção e seus efeitos no Assentamento Piquiá I - Marabá. Agenda Social, 12(2),11 - 24. file:///D:/Downloads/374-1271-1-PB\%20(1).pdf.

Bruno, F.H.S. (2013). Avaliação da composição mineral do adubo orgânico produzido a partir de resíduos de pescados e vegetais no desenvolvimento da cultura da cebolinha. Revista Brasileira de Higiene e Sanidade Animal, http://www.higieneanimal.ufc.br/seer/index.php/higieneanimal/article/view/105. http://dx.doi.org/10.5935/1981-2965.20130013

Cândido, M. G., Meira, J. C. (2017). Impactos ambientais: análise da geração e destinação dos resíduos sólidos produzidos na feira liv re do município de Caldas Novas/GO. Simpósio Interdisciplinar em Ambiente e Sociedade. Anais do Simpósio Interdisciplinar em Ambiente e Sociedade, Goiânia, Goiás, 1. file:///D:/Downloads/12036-Texto\%20do\%20artigo-35342-1-10-20181116\%20(3).pdf

Carvalho, E. N., Silva, F. Q., Sardinha, A. S., Bispo, C. J. C., Souza, H. N., Rocha, M. C., \& Santos, S. N (2019). Geração e coleta de resíduos sólidos urbanos (RSU) em Marabá - Pa. Anais do Fórum Internacional de Resíduos Sólidos. 10. João Pessoas, PB, Brasil. file:///D:/Downloads/1452-Texto\%20do\%20artigo5404-1-10-20191013.pdf

Chiarelotto, M. Bottini, W, C., Spicker, C. E., Duarte, S. S., Chiarelotto, M., \& Bortoli, M. (2018). Composting of household organic waste: effect on control parameters and final compound quality. Revista Agro@mbiente online, 12(4), 272-287. https://revista.ufrr.br/agroambiente/article/view/5126. http://dx.doi.org/10.18227/1982-8470rGRO.V12I4.5126

Conceição, M. M. M., Pereira Junior, A. (2020). Plano de gerenciamento de residuos sólidos em uma instituição de ensino superior. Brazilian Journal of Development, 6(7), 45643-45675. https://www.brazilianjournals.com/index.php/BRJD/article/view/13043. http://dx.doi.org/10.34117/bjdv6n7-261

Costa, S. R., \& Souza, P. A. R. O. (2012). Impacto dos resíduos de pescado: o caso da "feira do bagaço"! no município de Parintins no Amazonas. Desarrollo local Sostenible, 5(14), 1-11. https://ideas.repec.org/a/erv/deloso/y2012i1411.html

Costa, W. M. Vidal, J. M., A., Veiga, M. C. M., Rodrigues, J. M., Santos, J. F. (2016). Aproveitamento de resíduos de pescado: o artesanato com escamas de peixe. Revista Ciência em Extensão, 12(2), 8-17. file:///D:/Downloads/1239-10519-1-PB.pdf

Cunha, E. L A. B. (2013) Aspectos sanitários e de gestão ambiental do setor de pescado em uma feira livre no município de Manaus - AM. [Dissertação de Mestrado]. Universidade Federal do Pará, Belém, Pará, Brasil. http://ppcs.propesp.ufpa.br/ARQUIVOS/dissertacoes/2013/esther.pdf

Decker, A.T., Rodrigues, E. A., Almeida, J. C., Quadro, M. S. S., Leandro, D., Andreza, R., Barcelos, A. A. (2016). Avaliação dos possíveis impactos ambientais dos resíduos de pescado na localidade de Pelotas/RS. Revista Brasileira de Engenharia e Sustentabilidade,2(1), 1-10. file:///D:/Downloads/618634396-1-PB\%20(2).pdf

Decreto n. ${ }^{\circ}$ 9,013. Inspeção Industrial Sanitária de Produtos de Origem Animal. http://www2.camara.leg.br/legin/fed/decret/2017/decreto-9013-29-marco2017-784536-publicacaooriginal-152253-pe.html

Dias, M. (2018). 9 tipos de amostragem probabilística e não probabilística. http://www.opuspesquisa.com

Felici, E. M., Kuroda, E. K., Yamashita, F., \& Silva, S. M. C. P. (2013). Remoção de carga orgânica recalcitrante de lixiviado de resíduos sólidos urbanos prétratado biologicamente por coagulação química-floculação-sedimentação. Revista Engenharia Sanitária e Ambiental, 18(2), 177-184. https://www.scielo.br/pdf/esa/v18n2/a10v18n2.pdf. http://dx.doi.org/10.1590/S1413-41522013000200010

Ferri, G. L., Chaves, G. L. D., \& Ribeiro, G. M. (2015). Análise e localização de centros de armazenamento e triagem de resíduos sólidos urbanos para a rede de logística reversa: um estudo de caso no município de São Mateus, ES. Revista Production, 25(1), 27-42. https://www.scielo.br/pdf/prod/v25n1/0103-6513prod-0103-6513-2014-138913.pdf. http://dx.doi.org/10.1590/s0103-651320114005000014

Galvão, J.; Oetterer, M. (2017). Qualidade e processamento de pescado. Elsevier

Gibaldi, N. S., Bueno, C., Olifiers, N. (2020). Perfil dos visitantes e seus impactos negativos no Parque Natural Municipal Chico Mendes, Rio de Janeiro - RJ. Research, Society and Development, 9(10), e584910794. file:///D:/Downloads/7904-Article-124628-1-10-20201009.pdf. http://dx.doi.org/10.22448/rsd-v9i10.7904

Glowka, R. P., Weingartner, M., \& Muelbert, B. (2018). Produção e comercialização de pescado no município de Laranjeiras do Sul, Paraná. Revista Verde de Agroecologia e Desenvolvimento Sustentável, 13(4), 531-543. file:///D:/Downloads/Dialnet-ProducaoEComercializacaoDePescadoNoMunicipioDeLara7083422\%20(2).pdf. http://dx.doi.org/10.18378/rvads.v13i45764

Godoy, M. R. B. (2013). Dificuldades para aplicar a Lei da Política Nacional de Resíduos Sólidos no Brasil. Caderno de Geografia, 23(39), 1-12. http://periodicos.pucminas.br/index.php/geografia/article/view/4784\#: :text=Inexistia\%20um\%20órgão\%20central\%20que,oficial\%20como\%20no\%20setor\% 20 privado. 
Gonçalves, A. A. (2011). Tecnologia do Pescado: Ciência, Tecnologia, Inovação e Legislação. Atheneu.

Higuchi, L.H. (2015). Produção, caracterização nutricional e utilização de farinhas e óleos de resíduos de peixes neotropicais em dietas para Tilápia do Nilo. (Tese de Doutorado) Universidade Estadual Paulista. São Paulo, SP, Brasil. https://repositorio.unesp.br/handle/11449/132803

IBGE. (2013). Normas de apresentação tabular. (3a ed.). IBGE.

Jesus, T. B., Santos, T. N., \& Carvalho, C. R. V. (2018). Aspectos da comercialização de pescado em feiras livres do município de Feira de Santana-Ba. Revista Gestão \& Sustentável Ambiental, 7(2), 159-179. http://www.portaldeperiodicos.unisul.br/index.php/gestao_ambiental/article/view/6205 http://dx.doi.org/10.19177/rgsa.v7e22018159-179

Kefalas, H.C. (2011). Resíduos Orgânicos Da Atividade Pesqueira No Município De Pontal Do Paraná: Geração, Destinação Atual e Alternativas. (Monografia, Graduação em Oceanografia). Universidade Federal do Paraná, Pontal do Paraná, PR, Brasil. https://acervodigital.ufpr.br/handle/1884/36472

Lei n. 11.959, de 29 de junho de 2009. Dispõe sobre a Política Nacional de Desenvolvimento Sustentável da Aquicultura e da Pesca, regula as atividades pesqueiras, revoga a Lei $\mathrm{n}^{\circ} 7.679$, de 23 de novembro de 1988, e dispositivos do Decreto-Lei $\mathrm{n}^{\circ}$ 221, de 28 de fevereiro de 1967, e dá outras providências. http://www.planalto.gov.br/ccivil_03/_Ato2007-2010/2009/Lei/L11959.htm

Lei n. 12.305 de 02 de agosto de 2010. Institui a Política Nacional de Resíduos Sólidos; altera a lei n.9.605, de 12 de fevereiro de 1998; e dá outras providencias. http://www.planalto.gov.br/ccivil_03/_ato2007-2010/2010/lei/l12305.htm

Lima, L. K. F. (2013). Reaproveitamento de resíduos sólidos na cadeia agroindustrial do pescado, Palmas: Embrapa Pesca e Aquicultura.

Lins, J. A. P. N. (2010). Uso de peixes como biomarcadores para monitoramento ambiental aquático. Revista Acadêmica de Ciências Agrárias e Ambientais, 8(4), 469-484. https://periodicos.pucpr.br/index.php/cienciaanimal/article/view/11018. http://dx.doi.org/10.7213/cienciaanimal.v8i4.11018

Lopes, B. S., Alves, J. P. (2020). Ciclo do PDCA na indústria do pescado. Brazilian Journal of Animal and Environmental Research, 3(3), 1370-1379. https://www.brazilianjournals.com/index.php/BJAER/article/view/14444. http://dx.doi.og/10.34188/bjaerv3n3-054

Lucena, M. M. A. (2010). Percepção Ambiental por uma comunidade rural do entorno de uma Reserva Particular do Patrimônio Natural (RPPN), semiárido brasileiro. (Dissertação de Mestrado). Universidade Federal do Rio Grande do Norte. file://D:/Downloads/MycarlaMAL_DISSERT.pdf

Martins, C. W.S. (2015). A comercialização de peixes em feiras públicas, nos municípios de Feira de Santana e Cruz Das Almas, Bahia. (Trabalho de Conclusão de Curso). Universidade Federal do Recôncavo da Bahia. Salvador, BA. http://www.repositoriodigital.ufrb.edu.br/handle/123456789/1056?mode=full.

Matias-Pereira, J. (2016). Manual de Metodologia da Pesquisa Científica. (4a ed). Atlas

Matos, J. C., Benvindo, L. R. S., LVA, T, O., \& Carvalho, L. M. F. (2015). Condições higiênico-sanitárias de feiras livres: uma revisão integrativa, Revista Eletrônica Gestão \& Saúde, 6(3),2884-2893. https://periodicos.unb.br/index.php/rgs/article/view/3281

Medeiros Junior, E. F., Eiras, B. J. C. F., Rodrigues, E. C. \& Alves, M. M. (2015). Avaliação higiênico-sanitária do pescado comercializado na cidade de Bragança Pará. Nutritime Revista Eletrônica, 12(5), 4237-4243.Recperado de https://www.nutritime.com.br/arquivos_internos/artigos/323_-_4237-4243__NRE_12-5_set-out_2015.pdf

Melo, F. O., Alves, M. M., Guimarães, M. D. F., Carlos, F., \& Holanda, F. (2011). Aproveitamento do resíduo a partir do beneficiamento de pescado de uma indústria pesqueira no norte do Brasil. Revista Arquivos de Ciência do Mar, 44(3), 5-11. http://www.periodicos.ufc.br/arquivosdecienciadomar/article/view/148. http://dx.doi.org/10.32360/acmar.v44i3.148

Mendonça, D. S. M., Zang, J. K., Fonseca-Zang, W. A. (2017). Efeitos e danos da disposição de resíduos sólidos na área de lixão e aterro controlado no município de Inhumas - GO. Caderno de Geografia, 27(50), 486-499. http://periodicos.pucminas.br/index.php/geografia/article/view/p.23182962.2017v27n50p486. http://doi.org/10.5752/p.2318-2962.2017v27n50p486

MICROSOFT CORPORATION (2016). Project for Windows 10. Version 4.1. https://www.ebay.com/itm/Microsoft-Project-Version-4-1/174300951199?_ul=BR

Mota, J. L., Ferreira, S. D., \& Morales, U. S. (2020). As feiras livres: um estudo sobre a comercialização de pescado nas áreas urbanas do município de Macapá - PA. Brazilian Journal of Development, 6(10), https://www.brazilianjournals.com/index.php/BRJD/article/view/17822. http://doi.org/10.34117/bjdv6n10-099

Nascimento, M. S., Pereira, S. J. B., Santos, R. F., \& Vieira, A. M. (2018). Avaliação e caracterização do processo de compostagem de resíduos de peixes. PUBVET, 12(11),1-7. https://www.pubvet.com.br/artigo/5329/avaliaccedilatildeo-e-caracterizaccedilatildeo-do-processo-de-compostagem-de-resiacuteduosde-peixes\#: :text=Avaliação\%20e\%20caracterização\%20do\%20processo\%20de\%20compostagem\%20de\%20resíduos\%20de\%20peixes,-Marcelo\%20

dos\%20 Santos\&text=Os\%20parâmetros\%20avaliados\%20foram\%3A\%20temperatura,N\%20e\%20índice\%20de\%20mineralização. https://doi.org/10.31 533/Pubvet.v12n11a217.1-7

Oliveira, A. L. T., Sales, R. O., Freitas, J. B. S., \& Lopes, J. E. (2012). Alternativa sustentável para descarte de resíduos de pescado em Fortaleza. Revista Brasileira de Higiene e Sanidade Animal. 6(2), 1-16. file:///D:/Downloads/62-4826-1-PB.pdf. http://dx.doi.org/10.5935/1981-2965.20120003

Oliveira, G. F., Nascimento S. F., Mello, A. H., Pereira, V. D. N., \& Mendes, A. S. (2011). Caracterização Econômica e social dos pescadores do rio Tocantins em Marabá - Pará. Revista Agroecossistemas, 3(1, 18-23, 2011. file:///D:/Downloads/1238-5389-1-PB\%20(1).pdf

Oliveira, J. L. Almeida, A. B. B., Freire, L. L., Albuquerque, M. S., Barbosa, J, C., Pereira, M. S., \& Barbosa, U. P. S. (2018). Compostagem dos resíduos orgânicos em instituições de ensino: experiências do IFCE - Campus Juazeiro do Norte. Revista Ciência e Sustentabilidade, 4(1), 57-78. https://periodicos.ufca.edu.br/ojs/index.php/cienciasustentabilidade/article/view/287. https://doi.org/10.33809/2447-4606.41201857-78 
Patino, C., Ferreira, J. C. Qual a importância do cálculo do tamanho amostral? Journal Brasileiro de Pneumologia, 42(2), 162. https://www.scielo.br/pdf/jbpneu/v42n2/pt_1806-3713-jbpneu-42-02-00162.pdf. http://dx.doi.org/10.1590/S1806-37562016000000114

Pereira, A. S. Shitsuka, D, M., Parreira, F. J. \& Shitsuka. R. Metodologia da pesquisa científica. Santa Maria: UAB/NTE/UFSM.

Pinto, B. V. V., Vilarinho, Bezerra, A. E., Amorim, E., Valadão, R. C., \& Oliveira, G. M. (2017). O Resíduo de pescado e o uso sustentável na elaboração de coprodutos. Revista Mundi Meio Ambiente e Agrárias, 2(2), $15 . \quad$ http://periodicos.ifpr.edu.br/index.php?journa l=MundiMAA\&page=article \&op=view\&path\%5B\%5D=223. http://dx.doi.org/10.21575/25254790rmmaa.2017vol2n2223

Pinto, R. C. L. B., Santos, R. S., Maciel, W. L. S., Maciel, C. M. R. R., \& Maciel Júnior, A. (2011). Sistema de comercialização de peixes nas feiras livres na sede do Município de Itapetinga-Ba. Revista Enciclopédia Biosfera, $7(13), \quad 1249-\quad 1258$. https://www.conhecer.org.br/enciclop/2011b/ciencias\%20ambientais/O\%20sistema.pdf

Pires, D. R., Morais, A. C. N., Costa, J. F., Góes, L. C. D. S., \& Oliveira, G. M. (2014). Aproveitamento do resíduo comestível do pescado: Aplicação e viabilidade. Revista Verde de Agroecologia e Desenvolvimento Sustentável, $\quad 9(5), \quad 34 \quad-\quad 46$. https://www.gvaa.com.br/revista/index.php/RVADS/article/view/2956/0

Pires, I. C. G.; Ferrão, G. E. (2017). Compostagem no Brasil sob a perspectiva da legislação ambiental. Revista trópica Ciências Agrárias e Biológicas, 9(1), 01-18. file:///D:/Downloads/5685-19757-1-PB.pdf

Prodanov, C. C., \& Freitas, E. C. (2013). Metodologia do trabalho científico: Métodos e Técnicas da Pesquisa e do Trabalho Acadêmico. (2a ed.). Novo Hamburgo: Feevale.

Raiol, I. N. Castro, L. R. C., \& Neves, D. I S. (2019). Diagnóstico do gerenciamento de resíduos sólidos na feira livre 8 de maio no distrito administrativo de Icoaraci em Belém - Pará. Revista Gestão \& Sustentabilidade, 8(4), 182-198. http://www.portaldeperiodicos.unisul.br/index.php/gestao_amb iental/article/view/7425. http://dx.doi.org/10.19177/rgsa.v8e42019182-198

Resolução $n^{\circ} 326$ de 30 de julho de 1997. Regulamento técnico sobre as condições higiênico-sanitárias e de boas práticas de fabricação para estabelecimentos produtores/industrializadores de alimentos. https://bvsms.saude.gov.br/bvs/saudelegis/svs1/1997/prt0326_30_07_1997.html

Resolução Conama $n^{o}$ 275, de 25 de abril de 2001. Dispõe sobre o código de cores para os diferentes tipos de resíduos, a ser adotado na identificação de coletores e transportadores, bem como nas campanhas informativas para a coleta seletiva. http://www2.mma.gov.br/port/conama/legiabre.cfm?codlegi=273

Resolução n. ${ }^{\circ} 466$ de 12 de dezembro de 2012. Estabelece a aprova diretrizes e normas regulamentadoras de pesquisas envolvendo seres humanos: https://conselho.saude.gov.br/resolucoes/2012/Reso466.pdf

Resolução $\quad{ }^{\circ} \quad 510$ de 7 de abril de 2016. Modifica as diretrizes $\quad$ da $\quad$ resolução $\quad \mathrm{n} .{ }^{\circ} 466$. http://bvsms.saude.gov.br/bvs/saudelegis/cns/2016/res0510_07_04_2016.html

Rodrigues, E. A. (2013). Avaliação dos resíduos gerados no processo produtivo de pescado na colônia de pescadores Z3, Pelotas - RS. (Trabalho de Conclusão de Curso). Universidade Federal de Pelotas, RS. https://wp.ufpel.edu.br/esa/files/2013/10/TCC-EVELINE-ARAUJO3.pdf

Sanes, F. S. M., Strassburger, a. S., Araújo, F. B., Medeiros, A, B. (2015). Compostagem e fermentação de resíduos de pescado para produção de fertilizantes orgânicos. Revista Semina Ciências Agrárias, 36(3), 1241-1252. file:///D:/Downloads/16860-96709-1-PB\%20(4).pdf. http://dx.doi.org/10.5433$0359.2015 \mathrm{v} 3 \mathrm{n} 3 \mathrm{p} 1241$

Santos, A. P. B. (2016). Caracterização e aproveitamento do resíduo de pescado junto aos pontos de comercialização da Baixada Santista - SP. (Tese de Doutorado). Universidade de São Paulo, São Paulo, SP. https://www.teses.usp.br/teses/disponiveis/74/74131/tde-21022017-145040/pt-br.php, http://dx.doi.org/10.11606/T.74.2017.tde.21022017-145040

Santos, A. T. L., Henrique, N. S., Shhlindwein, J. A., Ferreira, E., \& Stachiw, R. (2014). Aproveitamento da fração orgânica dos resíduos sólidos urbanos para produção de composto orgânico. Revista Brasileira de Ciências da Amazônia, 3(1), 15-28. https://tratamentodeagua.com.br/wpcontent/uploads/2016/06/Aproveitamento-da-fração-orgânica-dos-resíduos-sólidos-urbanos-para-produção-de-composto-orgânico.pdf

Santos, D. B. Machado, S., Sampaio, a. h. r., \& Vieira, L. M. (2013). Avaliação das condições higiênico-sanitárias da feira livre da colônia dos pescadores no Município de Uruçuí- $\quad$ PI. $\quad$ Enciclopédia $\quad$ Biosfera,9(16), $2433-2442$. https://www.conhecer.org.br/enciclop/2013a/miltidisciplinar/AVALIACAO\%20DAS\%20CONDICOES.pdf

Santos, J. G. (2012). A Logística Reversa como Ferramenta para a Sustentabilidade: Um Estudo Sobre a Importância das Cooperativas de Reciclagem na Gestão dos Resíduos Sólidos Urbanos. REUNA, 17(12), 81-96. $\quad$ https://www.conhecer.org.br/enciclop/2013a/mil tidisciplinar/AVALIACAO\%20DAS\%20CONDICOES.pdf.

Siebert, T. H. R., \& Silva, R. A. (2019). Levantamento dos principais peixes comercializados na feira do pescado de Santarém - Pará, de setembro de 2017 a janeiro de 2018. Revista Brasileira de Engenharia de Pesca, 12(1), 62-74. https://ppg.revistas.uema.br/index.php/REPESCA/article/view/1834 http://dx,doi.org/1018817/repesca.v12i1.1834

Silva, A. M. C. B., Souza, R. A. L., Melo, Y, P, C., Zacardi, D. M., Paiva, R. S, \& Nakayama, L. (2010). Diagnóstico da Piscicultura na Mesorregião Sudeste do Estado do Pará. Tropical Journal of Fisheries and Aquatic Sciences. $10 \backslash(1)$, $55-65$. https://cepnor.ufra.edu.br/index.php?journal=tjfas\&page=article\&op=view\&path\%5B $\% 5 \mathrm{D}=1160 \#: \sim$ :text=Considerase\%20que\%20a\%20produção,por\%20órgãos\%20públicos\%20e\%20privados. http://dx.doi.org/1032519/tjfas.v10i1.1160

Silva, A, R. S., Melo, D. G., Moraes, F. J. S., Antônio, T., Coelho, T. P. M., \& Silva, G. S. (2015). Impactos ambientais referentes à não coleta de lixo e reciclagem. Ciências Exatas e Tecnológicas, 2(3), 63-75. file:///D:/Downloads/2136-Texto\%20do\%20artigo-6993-1-10-20150526\%20(1).pdf

Silva, C. A., \& Andreoli, C. V. (2010). Compostagem como alternativa à disposição final dos resíduos sólidos gerados na Ceasa. Revista Engenharia Ambiental, 7(2),27-40. file:///D:/Downloads/EA-2010-411.pdf 
Research, Society and Development, v. 10, n. 4, e51310414417, 2021

(CC BY 4.0) | ISSN 2525-3409 | DOI: http://dx.doi.org/10.33448/rsd-v10i4.14417

Silva, M. A., Vargas, P. H. B., Martins, A, L. S., \& Nascimento, K. L. (2020). Avaliação do controle de qualidade das frutas e hortaliças comercializados na feira livre de Valença/RJ. Research, Society and Development, 9(11), e1109119346. file:///D:/Downloads/9346-Article-132923-1-10-20201106\%20(1).pdf. http://dx.doi.org/10.33448/rsd-v9i11.9346

Silva, R. A. Bonnas, D. S., \& Silva, P. F. (2015). Aproveitamento dos resíduos gerados no processamento de postas de surubim (Pseudoplatystoma corruscans) para elaboração de nuggets. Revista Contextos da Alimentação, 3(2), 38-48. http://www3.sp.senac.br/hotsites/blogs/revistacontextos/wpcontent/uploads/2015/06/46_artigo_Contextos_ed-vol-3-n-2-ano-14.pdf

Soares, K. M. P., \& Gonçalves, A. A. (2012). Qualidade de segurança do pescado. Revista Instituto Adolfo Lutz, 71(1), 1-10. http://periodicos.ses.sp.bvs.br/pdf/rial/v71n1/v71n1a01.pdf

Soares, V. M., Pereira, J. G., Izidoro, T. B., Martins, O. A., Pinto, J. P. A., \& Biondi, G. F. (2011). Qualidade microbiológica de filés de peixe congelados distribuídos na cidade de Botucatu - SP. Revista Cientifica Ciências Biológica Saúde, 13(2),85-88. file:///D:/Downloads/1229-Texto\%20do\%20artigo-47541-10-20150703.pdf

Souza, E. R. O., Silva, B. P., Canto, O., \& Pontes, A. N. (2019). Resíduos de peixe do Mercado de Ferro, Complexo do Ver-o-Peso, Belém, Pará. Revista $\begin{array}{lllll}\text { Verde Agroecologia de e } & \text { Desenvolvimento } & \text { Sustentável. } & 14(4), & 562-570 .\end{array}$ https://editoraverde.org/gvaa.com.br/revista/index.php/RVADS/article/view/6687/6934

Valente, B. S., Xavier, E. G., Pereira, H. S., \& Pilotto, M. V. T. (2014). Compostagem na gestão de resíduos de pescado de água doce. Boletim do Instituto de Pesca, 40(1), 95 - 103. https://www.pesca.sp.gov.br/40_1_95-103.pdf

Valente, B. S., Xavier, E. G., Pereira, H. S. \& Pilloto, M. V. T. (2016). Compostagem de resíduos da filetagem de pescado marinho e casca de arroz. Revista Brasileira de Saúde e Produção Animal, 17(2), 237-248. https://www.scielo.br/pdf/rbspa/v17n2/1519-9940-rbspa-17-2-0237.pdf. http://dx.doi.org/10.1590/A1519-99402016000200011

Vallejo, F., \& Monteiro L. (2014). Avaliação das Demandas e Potenciais Associados ao Gerenciamento de Resíduos Sólidos em Cidades Emergentes: O Caso do Município de Rio das Ostras, RJ. Revista Eletrônica Sistemas \& Gestão, 9(2), 200-208. https://www.revistasg.uff.br/sg/article/view/V9N2A4. http://dx.doi.org/107177/sg.2014.V9.N2.A4

Vidotti, R. M., \& Lopes, I. G. (2016). Resíduos orgânicos gerados na piscicultura. Pesquisa \& Tecnologia, 13(2). http://www.aptaregional.sp.gov.br/acesseos-artigos-pesquisa-e-tecnologia/1696-residuos-organicos-gerados-na-piscicultura/file.html\#: :text=Resíduos\%20orgânicos\%20da\%20p iscicultura\%20são ,o\%20prato\%20final $\% 20 \mathrm{do} \% 20$ consumidor. 